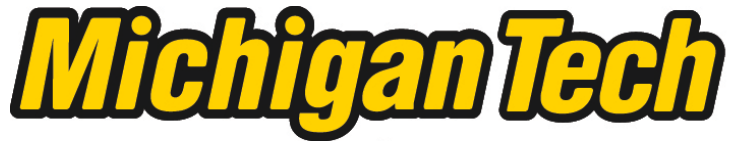 \\ Michigan Technological University Create the Future Digital Commons @ Michigan Tech
}

Dissertations, Master's Theses and Master's Reports - Open

Dissertations, Master's Theses and Master's

Reports

2011

Improving learning by connecting chemistry curriculum to students' experiences

Nicole N. Olszowy

Michigan Technological University

Follow this and additional works at: https://digitalcommons.mtu.edu/etds

Part of the Science and Mathematics Education Commons

Copyright 2011 Nicole N. Olszowy

\section{Recommended Citation}

Olszowy, Nicole N., "Improving learning by connecting chemistry curriculum to students' experiences ", Master's report, Michigan Technological University, 2011.

https://doi.org/10.37099/mtu.dc.etds/530

Follow this and additional works at: https://digitalcommons.mtu.edu/etds

Part of the Science and Mathematics Education Commons 


\title{
Improving Learning by Connecting Chemistry Curriculum to Students’ Experiences
}

\author{
By \\ Nicole N. Olszowy

\begin{abstract}
A REPORT
Submitted in partial fulfillment of the requirements for the degree of

MASTER OF SCIENCE IN APPLIED SCIENCE EDUCATION
\end{abstract}

MICHIGAN TECHNOLOGICAL UNIVERSITY 2011

Copyright $@$ Nicole N. Olszowy 2011 
This report "Improving Learning by Connecting Chemistry Curriculum to Students' Experiences," is hereby approved in partial fulfillment of the requirements for the Degree of MASTER OF SCIENCE IN APPLIED SCIENCE EDUCATION.

DEPARTMENT OF COGNITIVE AND LEARNING SCIENCES

Report Advisor

Dr. Kedmon Hungwe

Department Chair

Dr. Brad Baltensparger

Date 


\begin{abstract}
Improving Learning by Connecting Chemistry Curriculum to Students’ Experiences

By

Nicole N. Olszowy
\end{abstract}

The purpose of the study was to design, implement, and assess the effects of a teaching unit about fuel sources and chemical energy on students' learning. The unit was designed to incorporate students' experiences in a way that was aligned with the Michigan High School Content Expectations.

The study was completed with all of the students taking General Chemistry in a rural Michigan high school in the 2010-11 school year. There were 138 participants total. The participants were mostly Caucasian and the majority were in the $11^{\text {th }}$ grade. Of these, 77 constituted the experimental group and were taught the unit. The additional 61 participants in the control group were given the posttest only.

Data was derived from the results of pre/post tests, final assessment projects, and the researcher's observations. A pretest that contained questions about the fuel sources was administered at the beginning of the unit. An identical posttest was administered at the completion of the unit. A final assessment project required students to choose the best fuel source for the area, and support their opinion with facts and data from their research or the learning activities and labs performed in class.

The results of the study revealed that the teaching unit did produce significant learning gains in the experimental group. The results also indicated that the teaching unit added value to the current General Chemistry curriculum by expanding what students 
were learning. The instructional goals of the unit were aligned with the Michigan High School Content Expectations. The results also revealed that the students were able to learn to support their thinking and decisions with explanations based on the data and labs. These are essential science literacy skills. The study supported the view that connecting the required curriculum with students' experiences and interests was effective, and that students can learn important science literacy skills, such as providing support for arguments and communicating scientific explanations, when given adequate teacher support. 


\section{Acknowledgements}

I must thank my husband for being the most supportive person I know. He has done without me for weeks at a time while I was taking classes up at Michigan Tech. He has also been there to take over when I needed to spend time writing, and always listened to my complaints and frustration during the process. He is my rock.

My mother is an amazing woman and also needs to be thanked. She watched my son for endless hours at a time and proof-read my paper, while I diligently worked on this project. I absolutely could not have done this without her.

Thank you to my advisor, Kedmon Hungwe, who was so helpful in determining a project, and always prompt with revisions and advice. With his help, I was able to find my voice for this research project.

I also would like to thank Joan Chadde who organizes the summer teacher institutes at Michigan Tech. Joan presents amazing teacher institutes that always give me great ideas to take back to my classroom and it was my Future Fuels from Forests Institute that inspired this teaching unit.

Finally, I would like to thank the instructors and professors at Michigan Tech who were an inspiration, and showed me how to incorporate active learning in my classroom. My time at Michigan Tech made me a better science teacher. 
Table of Contents

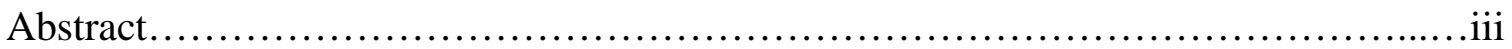

Acknowledgements..........................................................

List of Tables.....................................................................

Chapter 1 - Introduction......................................................1

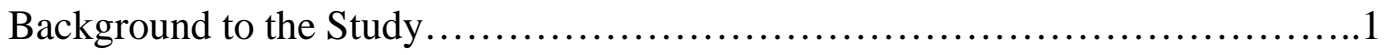

Research Questions.......................................................

Content Expectations....................................................4

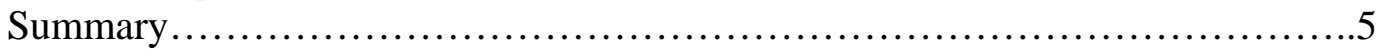

Chapter 2 - Review of Related Literature........................................6

Introduction.............................................................

Connecting Instruction................................................. 7

Problem-Based Learning and Achievement.................................... 9

Science Literacy and Quality Explanations....................................12

The Role of the Teacher.............................................. 14

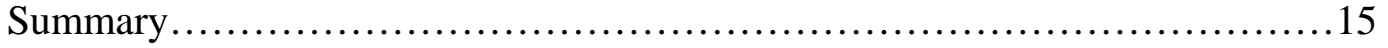

Chapter 3 - Methods..........................................................18

Introduction.......................................................... 18

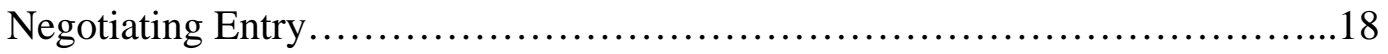

Research Design.......................................................19

Participants..........................................................20

Instruments...........................................................

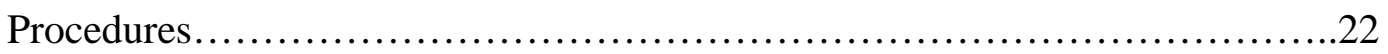

Data Collection and Analysis............................................25

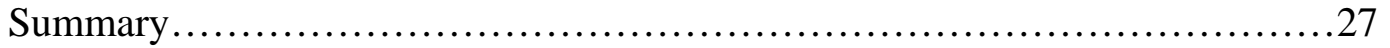

Chapter 4 - Results..........................................................28

Introduction........................................................28

Pre/Post Test Results..................................................28

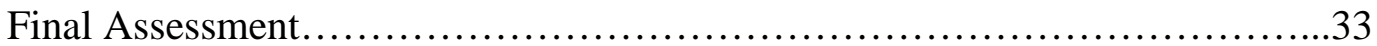

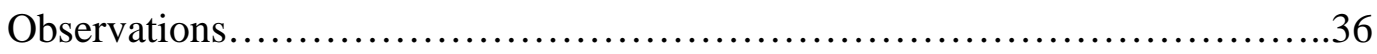

Summary ......................................................... 38

Chapter 5 - Conclusion........................................................40

Introduction......................................................... 40

Discussion of Results................................................40

Limitations of the Study................................................ 41

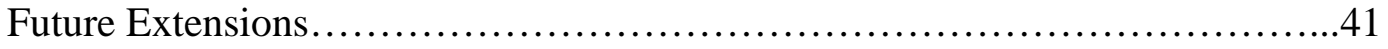

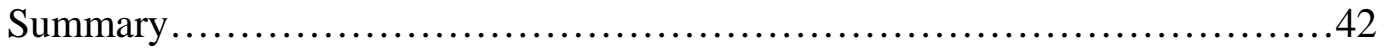




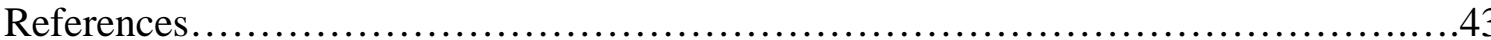

Appendices

Appendix A: Pre/Post Test............................................45

Appendix B: Final Assessment Description................................46

Appendix C: Final Assessment Grading Rubric..............................47

Appendix D: Fuel Investigations Unit Plan................................48

Appendix E: Internship Reference and Journal of Activities....................61 
List of Tables

Table 1: Research Design.................................................19

Table 2: Pre/Post Test Comparison: Experimental Group...........................29

Table 3: Normalized Gains..................................................32

Table 4: Final Assessment Scores..............................................33

Table 5: Final Assessment Format Comparison..................................35

Table 6: Posttest/Project Comparison............................................35 


\section{Chapter 1}

Introduction

Energy in Chemistry always seems very separate from the energy we talk about in everyday life, mainly, sources of fuel. In Chemistry, we discuss chemical potential energy from molecules, and never really relate it to other sources of energy. The goal of this research was to develop a bridge between the topics of chemical energy and sources of fuel. I believe that this approach enhanced the students' understanding of Chemistry.

The topic of fuels was relevant to the students' lives. Right now, with a looming fuel shortage and a strong desire to decrease our country's dependency on foreign fuels, alternative energies that can be produced on home soil are a very hot topic. Not only did I want students to be informed in Chemistry concepts, but I wanted them to be informed citizens on current world topics. These are central goals of the science literacy standards.

To achieve these goals, I developed a curriculum proposal, in the form of a unit lesson plan that I taught and evaluated. I intended to determine if teaching the unit plan increased the students' understanding of the topic of chemical energy. My research attempted to answer the following question: What instructional strategies will support the development of the students' abilities to make and adequately support informed decisions about fuel sources?

\section{Background to the Study}

I was a science teacher at Fowlerville High School in Fowlerville, Michigan for five years. During that time, I taught General Chemistry for all five years, Honors 
Chemistry for three years, and I developed a course in Advanced Placement Chemistry and taught it for two years. I was also the Science Olympiad coach for three years, the advisor for the Environmental Club for one year, and I started a school-wide recycling program. My goal as a teacher, coach, and advisor was to motivate students by involving them in the process of learning.

In the summer of 2008 , I completed an internship working with the environmental education section of the Michigan Department of Environmental Quality (DEQ). During my internship, I was exposed to oil-drilling sites, gas-tank removal, air quality analysis of factories, and soil sampling and chemical analysis. I also worked with a group of educators to update the Michigan Environmental Education Curriculum Support (MEECS) standards and benchmarks to the current Michigan Content Expectations.

I wanted to find a way to incorporate all of the many experiences I had seen through my internship, with the Chemistry content I was teaching. The MEECS teaching lessons were a great example of how to include environmental education with the science content. The only problem was that they were geared towards upper elementary to middle school students. I needed to find environmental subjects for my upper level high school students.

My courses at Michigan Technological University (MTU) focused on complex environmental topics which I could use in my teaching, like watershed analysis, future fuels, and engineering. It was my Future Fuels from Forests course that inspired the teaching unit about fuel sources. Finally I had a topic for a teaching unit, but I needed to find an un-conventional way of presenting the unit. 
Every year I would ask my students to write one or two research essays and they also needed to write lab reports throughout the year. I won't lie; the quality of my students' writing was horrible and I just accepted it. Then, my last year of teaching, I started to focus on writing more. I had my students write conclusions for the labs and I would give them formative feedback and have them do re-writes. I started to see improvements. I also noticed that students wrote better when they were explaining the labs that they had designed themselves. It occurred to me that it was easier to write about something they were involved or interested in. This was my motivation for presenting the subject as a problem to solve, and for the focus on student opinions and quality explanations.

\section{Research Questions}

There were two questions that the research attempted to answer. First, how could an instructional unit that addresses important conceptual knowledge in Chemistry, be constructed in ways that relate to the students' experiences, and also improve student learning? Furthermore, I wanted to investigate ways of developing the unit so that it would be aligned with the Michigan High School Content Expectations while at the same time expanding the scope and depth of student understanding. My hope was that this research would provide a model for integrating real-world events or problems into the Chemistry curriculum that other teachers could use. 


\section{Content Expectations}

The teaching unit was designed to be aligned with the Michigan High School

Content Expectations. I used an instructional strategy that did not rely on a textbook, but instead focused on a current environmental issue that would incorporate student experiences and interests into the required content. The research was designed to determine if this method was effective. The following is a list of the current Michigan High School Content Expectations that were covered in the teaching unit.

Science Inquiry, Reflection, and Social Implications

$\mathrm{C} 1.1 \mathrm{E}$-Describe a reason for a given conclusion using evidence from an investigation.

$\mathrm{C} 1.2 \mathrm{~B}$ - Identify and critique arguments about personal or societal issues based on scientific evidence.

$\mathrm{C} 1.2 \mathrm{C}$ - Develop an understanding of a scientific concept by accessing information from multiple sources. Evaluate the scientific accuracy and significance of the information.

$\mathrm{C} 1.2 \mathrm{E}$ - Evaluate the future career and occupational prospects of science fields.

$\mathrm{C} 1.1 \mathrm{~g}$ - Identify scientific tradeoffs in design decisions and choose among alternative solutions.

$\mathrm{C} 1.2 \mathrm{k}$ - Analyze how science and society interact from a historical, political, economic, or social perspective.

\section{Chemistry Content}

$\mathrm{C} 2.2 \mathrm{~B}$-Describe the various states of matter in terms of the motion and arrangement of the molecules (atoms) making up the substance.

P4.p2C -Separate mixtures based on the differences in physical properties of the individual components.

C5.2A -Balance simple chemical equations applying the conservation of matter.

$\mathrm{C} 3.1 \mathrm{c}$-Calculate $\Delta \mathrm{H}$ for a chemical reaction using simple coffee cup calorimetry.

C3.1d -Calculate the amount of heat produced for a given mass of reactant from a balanced chemical reaction.

C3.2a - Describe the energy changes in photosynthesis and in the combustion of sugar in terms of bond breaking and bond making.

$\mathrm{C} 3.4 \mathrm{c}$-Write chemical equations including the heat term as a part of equation, or using $\Delta \mathrm{H}$ notation.

C5.6b-Predict products of reactions. 


\section{Cross-Curricular Extensions}

Social Studies Content - Civics

P1.1 - Use close and critical reading strategies to read and analyze complex texts pertaining to social science; attend to nuance, make connections to prior knowledge, draw inferences, and determine main idea and supporting details.

P1.4 - Communicate clearly and coherently in writing, speaking, and visually expressing ideas pertaining to social science topics, acknowledging audience and purpose.

P1.5 - Present a coherent thesis when making an argument, support with evidence, articulate and answer possible objections, and present a concise, clear closing.

P2.1 - Understand the scientific method of inquiry to investigate social scientific and historical problems.

P3.2 - Deeply examine policy issues in group discussions and debates to make reasoned and informed decisions.

P3.3 - Write persuasive/argumentative essays expressing and justifying decisions on public policy issues.

\section{Summary}

The research investigated the effects of the teaching unit on fuel sources, teaching Chemistry content through the students' experiences and interests. My goal was to determine if the teaching unit added value to the current curriculum, and if there were significant learning gains as a result of the teaching unit. The research report is in five parts. Chapter 2 will focus on a review of the related literature. Chapter 3 will describe the research methods used. Chapter 4 will discuss the results and analysis. Finally, Chapter 5 will summarize the conclusions formed from the research. 


\section{Chapter 2}

\section{Review of Related Literature}

\section{Introduction}

Throughout my education courses, internship with the Michigan Department of Environmental Quality (DEQ) and teaching, it has become apparent that teaching science to students is best accomplished when the science concepts start with a foundation in the students' prior knowledge which is then related and connected to current events, issues, or experiences that interest the students. These connections allow the teacher to give purpose to learning the current curriculum, and the students to form a stronger base in the content. According to the Michigan Department of Education's High School Science Content Expectations (2006):

Students who have useful and connected knowledge should be able to apply knowledge in new situations; to solve problems by generating new ideas; to make connections among what they read and hear in class, the world around them, and the future; and through their work, to develop leadership qualities while still in high school (p.3).

In the following sections, I will summarize what I have learned about the topics of “Connecting Instruction", "Problem-Based Learning and Achievement”, "Science Literacy and Quality Explanations", and "The Role of the Teacher". 


\section{Connecting Instruction}

The goal of today's science education system is to teach students the required curriculum in a manner that encompasses real-life skills and situations, in order to increase the amount of retained information and transferability of skills. The National Science Education Standards (National Research Council, 1996) state that:

Science content must be embedded in a variety of curriculum patterns that are developmentally appropriate, interesting, and relevant to students' lives ... regardless of organization, the science program should emphasize understanding natural phenomena and science-related social issues that students encounter in everyday life. (p.

$$
\text { 212-213) }
$$

In a study of Junior High students' processes of argumentation and cognitive development, researchers found that students were using their prior knowledge and experiences when engaging in argumentation. The study also found that activities that required students to form an opinion for or against an argument, enabled students to combine and expand their existing knowledge with their science understanding (Von Aufschnaiter et al, 2008). This means that the average person will naturally use prior knowledge when confronted with a new situation and that this prior knowledge helps them to learn and retain more of the new information. Science curriculum must be related to student's prior knowledge in order for effective learning to occur.

Another study that looked at the effects of teaching through misconceptions found similar results when students were presented with common misconceptions of various 
science topics. The results showed that overall, students achieved greater learning gains when exposed to a situation that addressed misconceptions than one which presented only correct scientific information (Muller et al, 2008). When misconceptions of students are discussed, the teacher is able to connect the correct information to what the students already knew about the topic, making the learning more effective.

An additional study of two urban eighth-grade classrooms investigated the effects of using real-life situations to enhance the current science curriculum. The researchers, Rivet and Krajcik (2008), called the teaching approach "contextualized instruction" and defined it as the "utilization of particular situations or events that occur outside of science class or are of particular interest to students to motivate and guide the presentation of science ideas and concepts" (p. 80). It is the combination of many teaching practices, like inquiry and problem-based learning, with students' prior knowledge and interests, and has a focus on the curriculum. The study found that students were able to learn more effectively if the instruction involved a real-life situation or problem that had meaning to the students outside of school which related to the science concept, over an extended period. These situations or problems were found to produce more complete learning by creating links to connect information and relationships between new science concepts, prior knowledge and experiences, and real-world examples (Rivet \& Krajcik, 2008).

Students learn by making connections and categorizing new information. It follows then, that we should be teaching with those same connections. The more we can connect real-world situations that deal with the current curriculum with what students already "know" about a topic (whether they are facts or misconceptions), and present these issues in a problem-based or inquiry manner, the more our students will learn. 
Problem-Based Learning and Achievement

There have been many case studies that have looked at the benefits of students learning concepts in science for the purpose of solving a problem or answering a question. The idea is that the students will see a purpose for the learning, which will allow them to retain more of the information learned, therefore, scoring better on standardized tests. Presenting information in the form of problem-solving is also meant to teach students critical thinking skills.

Project EXCITE was a seven-year teacher professional development that prepared middle grade $\left(4^{\text {th }}-9^{\text {th }}\right)$ teachers to design and implement problem-based, environmental heath curricula to their students. In the research, twelve schools over a six-year period were involved in testing the effects of Project EXCITE. The study found that performance on the state proficiency test for all subject areas was enhanced during the periods of EXCITE implementation, and the percentage of students at a "below proficient" level was decreased. The students' scientific process skills were tested using the Performance of Process Skills test (POPS) (Mattheis \& Nakayama, 1988). The study found that there was a significant increase in the students' science process skills over the course of the project (Keil, Haney, \& Zoffel, 2009). This study shows a key factor of problem-based learning. It is vitally important that teachers should have proper training and support, through professional development, if they are to initiate problem-based learning; and if teachers have that training and support, they are able to implement problem-based learning in an effective way that has been shown to increase standardized testing scores and science process skills. 
The Capital City case study involved Physical Chemistry students working in groups in order to find a new energy source for a hypothetical city. The researchers found that students welcomed the opportunity to "put theory into practice" by studying physical Chemistry in an applied context and work as part of a group. They also found that students felt more confident with problem-solving and more comfortable with the required calculations because of the applied context (Belt et al, 2005). This study focused more on the students' perceptions of the learning experience through the use of questionnaires and researcher observations. The results highlight the importance of students being able to see a purpose for the learning experience. If there is a purpose and a real-life context, then it is easier for students to determine what methods or formulas are needed in a particular situation to solve the problem. This skill would be a requirement of many of the engineering, science, and technology careers today. As teachers, we have to remember that the goal should be to prepare students for their futures as workers and citizens, not to fill their heads with route memorization and facts.

One of the most useful resources for a teacher implementing problem-based learning in the classroom is technology. It can help increase the students' interest in the topic by relating to their love of technology, or it can also make it possible to do projects and experiments that you would not normally have the time, funds, or equipment for. One group used web-based Geographic Information Systems (GIS) maps to help them investigate environmental issues and problems in a local watershed. They were able to enhance their problem-based learning experience through the use of technology, which allowed the students to "analyze and synthesize large amounts of data that would be much more difficult in other formats" (Bodzin \& Anastasio, 2006, p.299). Another study 
used a computer program to present digital video clips of real-life events and presented students with predict-observe-explain tasks and scenarios in order to study the students' analysis of the tasks. This study found that students were able to have more in-depth conversations in analyzing the tasks because of the real-life events presented to them on the video clips (Kearney, 2004). Both of these studies show that technology can enhance the problem-based learning experience. If teachers are properly trained, technology can make the sometimes difficult task of preparing a problem-based curriculum that much easier, which gives them more time to focus on helping the students throughout the process.

Almost all of the previous studies that I researched have one thing in common, the environment. According to the National Science Foundation, in the coming decades, the public will be required to understand complex environmental issues and plans, and be required to make decisions that affect themselves and others on a local to global scale in reference to those environmental issues (Phirman and AC-ERE, 2003). So, not only should we be presenting students with problems to solve, but those problems should involve the effects on the environment surrounding them. It is no longer just a concern of the "tree-huggers" to worry about what effects we have on the earth. The number of global companies that have implemented "green" initiatives is a testament to this. When you present students with environmentally-based problems, you show them that those problems are important.

The research shows that science curriculum that involves students being presented with problems to solve, preferably environmentally-based, has been shown to be effective in increasing student interest, standardized test scores, and science process skills. The 
curriculum is most effective when teachers have adequate training and support to implement the procedures. When these requirements are combined, students will become competent future citizens.

\section{Science Literacy and Quality Explanations}

"Scientific literacy implies that a person can identify scientific issues underlying national and local decisions and express positions that are scientifically and technologically informed. Scientific literacy also implies the capacity to pose and evaluate arguments based on evidence, and to apply conclusions from such arguments appropriately" (National Research Council, 1996, p. 22). In other words, we do not just want to teach students science for the purpose of learning, but for the purpose of someday helping them to be informed citizens who make educated decisions.

In the classroom, one of the components of scientific literacy is scientific discussions. In a study of two senior science classes, students worked with partners on computer-based predict-observe-explain (POE) tasks and the researcher observed and made conclusions of the group discussions. The study found that the students had "rich" conversations for the "predict" and "observe" sections of the tasks, especially when they were asked to draw their predictions. However, the study found that the students did not have the same quality discussions when it came to the "explain" part of the tasks (Kearney, 2004). This study shows that teachers are effective when it comes to showing students how to predict and observe, but that the skill of being able to explain things is lacking in our students. The researcher concluded that students need extra help when it 
comes to composing explanations and suggested that teachers explore ways for students to communicate between groups in order to facilitate better explanations.

Another component of scientific literacy in the classroom is written explanations usually accomplished in journals or notebooks. When researchers analyzed students' science notebooks in eight classrooms that had all taught the same inquiry-based curriculum, they found that only $18 \%$ of the students provided explanations in complete form which included claim, evidence, and reasoning. Further study found that $80 \%$ of the students provided some sort of explanation, with the majority missing reasoning from the data to support their claims (Ruiz-Primo et al, 2010). In another study that focused on students' ability to write scientific arguments to explain phenomena with the use of specific curriculum, researchers found that students consistently scored lower when it came to "reasoning", and higher when it came to "claim" and "evidence" (McNeill, 2009). These studies showed that while students were instructed and guided in the process of writing explanations, they were lacking in these skills, specifically the ability to support their claims with reasoning.

Science literacy is one of the most important goals of the National Science Standards. It is the key factor in students growing-up to become independent learners who are informed and educated citizens. Being able to explain themselves and their decisions is an important part of this goal. According to multiple studies, students are not able to explain themselves completely. More specifically, it has been found that they are not able to support their decisions or opinions with reasoning based in fact. If we are to improve science education, then this deficiency must be dealt with. 
The Role of the Teacher

It goes without saying, that a teacher can make all the difference. Effective teachers have been known for having creative lessons that involve the students and get them interested in the topic. They care about the students, and encourage them to have questions. I have often had students claim to learn well from one teacher, and not at all from another teacher, even though they were teaching the same concepts. What can teachers do or improve on, so they can all be called "effective"?

In a study of eight classrooms that focused on the link between the quality of scientific explanations and students' learning, there were vast differences in the results among the classes, even though they were all implementing the same scientific-inquiry based curriculum. The classrooms that had a teacher who instructed the students in how to write explanations and then gave them practice and feedback saw the most quality explanations in their students' notebooks. The researchers concluded that the best prompts for instruction and assessment were those that "scaffold students to provide pieces of information relevant to the explanations, but that also allowed the students to do their own thinking” (Ruiz-Primo et al, 2010, p.605). They found those classrooms that had less guidance or the other extreme, the classrooms with too much guidance (giving students answers), "promoted copying from the board and did not allow students to incorporate their own thinking" (Ruiz-Primo et al, 2010, p.606). This study shows that not only is it important for students to know what a complete explanation is composed of, but they must also be shown examples and get practice and feedback in order to write complete explanations effectively. 
Another study of an 8-week Chemistry curriculum that followed six different teachers concluded that the students' abilities to write scientific explanations improved the greatest when their teachers provided a rationale for engaging in scientific explanation and when their teachers explicitly defined the different components of a scientific explanation. This study found that even how a teacher defined a scientific explanation had a major effect on the quality of student explanations. The conclusion was that educative materials and curriculum can have a positive impact on teachers' classroom support, but that how the teachers use these materials is what ultimately influences student learning (McNeill, 2009). This study shows that there needs to be a reason for students to give an explanation and that the core definition of what an explanation is composed of, is very important in the ability of students to write complete explanations.

Everything worth doing, takes time. The same is true for teaching and results. If science teachers want to be effective, then they must take the time to teach students not only how to write a complete explanation, but also show students examples, have them practice, and give them formative feedback on that practice. The research has shown that students are able to write complete explanations when they are in this type of classroom.

Summary

There are many factors that affect learning. Instruction that makes connections, implementation of problem-based learning, teaching of scientific literacy, specifically explanations, and the role of the teacher, have all been found to have their effects on 
learning scientific knowledge and literacy. Together, they create a science classroom that will produce future informed citizens.

Connected instruction allows the students to learn in a natural way. When teachers take the time to find connections between the science curriculum and real-world situations or problems and use those to guide the instruction, then students are able to learn more by connecting the new information with what they already knew about the topic. These methods have been shown to increase the amount of learning that occurs, by engaging students with the learning task and providing cognitive supports to organize the ideas and concepts.

Problem-based learning allows the students to learn content for the purpose of answering a question, not just because they are asked to. It increases student interest which facilitates students being able to apply their knowledge effectively. More importantly, it has been shown to increase scores on standardized tests and science process skills. The goal of teaching should be to produce students who can think on their own, and know how to work to solve a problem they are presented with. This is what will be required of them for the rest of their lives. Problem-based learning is a teaching method that will accomplish this goal.

When presented with a problem or scientific phenomena, students are lacking the skills required for writing complete explanations. Teachers have focused their attentions on predictions and observations, and have just told students to write explanations. This is not enough. Why are explanations important? They are the support and proof of a student's claim and are what turn any opinion into an educated conclusion. 
Multiple studies have shown that the students in classrooms that specifically teach them what a complete explanation is composed of, show them examples, and give them practice and feedback writing explanations, are able to write complete explanations effectively. Any process less than this, creates incomplete or total lack of explanations. The teacher, therefore, is able to make the choice if they will take the time to teach their students about explanations effectively or just skim over the requirement.

The research shows that connecting instruction and problem-based learning is effective and the skill of complete explanations is lacking in students. The purpose of this study was to investigate the correlation between connecting instruction and achievement. The study also investigated students' abilities to make informed decisions about a current topic and support that decision with explanations, and what role the teacher had on the quality of those explanations. 


\section{Chapter 3}

\section{Methods}

\section{Introduction}

I conducted the study at Fowlerville High School which is part of the Fowlerville Community Schools District in Livingston County, Michigan. Fowlerville has a general population of approximately 13,000 people and is located in mid-Michigan between Lansing and Brighton. Many of the residents work in the auto industry, and the area was hit hard with the automotive industry crisis that started in 2008. There is also a large farming community in the area. There are approximately 3000 students in the entire district. The high school contains grades nine through twelve and has a population of approximately 900 students. The students are mostly Caucasian, and 29\% receive free or reduced lunch in the high school.

\section{Negotiating Entry}

At the time of the study, I was not currently working and had been laid off from my previous position because of budget cuts and decreased enrollment. Fowlerville High School is where I had taught General Chemistry, Honors Chemistry, and Advanced Placement Chemistry for five years, therefore I had many contacts within the school system. I was given permission by the principal to conduct my research with the current General Chemistry students. 


\section{Research Design}

The data for the study was derived from two comparable cohorts, one of which was the experimental group, and the other a control group. A pre/post test design with non-random selection was used for the experimental group. A whole class participated based on convenience and suitability for addressing the research questions. A posttest only control group was also used. With regard to the experimental group, administering the pretest, then treatment, and finally the posttest enabled me to determine if there were significant learning gains as a result of the teaching unit. With respect to the posttest only control group, comparing the posttests of the experimental group to the posttests of the control group allowed me to determine if the teaching unit added value to the curriculum in ways that enhanced student learning beyond what they would normally receive under the regular curriculum. The design is summarized in Table 1.

Table 1: Research Design

\begin{tabular}{cccc} 
& Pretest & Treatment & Posttest \\
\hline Experimental Group & $\mathrm{O}_{1}$ & $\mathrm{X}$ & $\mathrm{O}_{2}$ \\
Control Group & & & $\mathrm{O}_{2}$ \\
\hline
\end{tabular}

The pretest for the experimental group was conducted on November 1, 2010. The teaching unit was the treatment and was presented over eight school days on November $1-10,2010$ according to the schedule listed on page 20 . 


\section{Teaching Unit Schedule}

Day 1 - Pretest Administered

Unit and Final Assessment Introduced

Day 2 - Internet Research

Day 3 - Internet Research

GIS Map Analysis

Day 4 - Compare Energy Stored in Two Fuels Lab

Day 5 - Compare Combustion By-Products Lab

Day 6-8 - In-Class work on Final Assessments

Day 8 - Posttest Administered

Final Assessments Turned In

The posttest for the experimental group was conducted on November 10, 2010. The control group was given the posttest only on March 25, 2011. The later date for administering the control group posttest enabled me to determine how much the students in the control group had learned three months into the second semester, compared to the experimental group who were tested in the first semester of an equivalent General Chemistry course.

\section{Participants}

The participants for this study consisted of all students enrolled in the General Chemistry course at Fowlerville High School in Fowlerville, Michigan. The experimental group consisted of seventy-seven students in three classes all with the same teacher, in which there were two sophomores, sixty-five juniors, and ten seniors. Thirtynine percent of the experimental subjects were female, and sixty-one percent were male. 
Some of the students were absent for a majority of the lessons, and therefore were removed from the data. There was also one student from Burma, who did not speak much English, and was also removed from the data because she was given an alternate final assessment. There were no other accommodations given, even though there were twenty students with Individualized Education Plans (IEPs) or 504 plans. The lessons were designed to be accommodating to all students and their abilities. The control group consisted of sixty-one students in three classes with a different teacher than the experimental group, in which there was one sophomore, fifty-four juniors, and six seniors. Thirty-nine percent of the control subjects were female, and sixty-one percent were male.

Instruments

The measurement devices for this study were a pre/post test (Appendix A), and a final assessment project (Appendix B). The pre/post test was comprised of nine shortanswer questions dealing with the fuel sources of fossil fuels, conventional ethanol, and cellulosic ethanol, and was graded out of fifteen points. The pre/post test was used to determine the learning gains of the students. The final assessment project required students to form an opinion about which of the three fuel sources would be best for midMichigan and then support their opinion with explanations based on the information they obtained during the learning activities. The final assessments were graded with a rubric (Appendix C) out of fifty points. The final assessment was used to determine the students' abilities to make informed decisions and write quality explanations. I also kept a detailed journal of the activities and student responses that supplied anecdotal data. 
Procedures

On the first day, the students were given the pretest and told to leave anything blank that they did not know. Most students left the entire pretest blank. With only a few exceptions, if students knew anything, it was that ethanol had something to do with corn. Then, we had a group discussion of ethanol and fossil fuels. With a little guidance from myself, and building off of each other's answers, the classes came up with general opinions and "facts" about fossil fuels and ethanol. For ethanol, students brought up E85 and said that it was cheaper but you get less mileage. They also knew that ethanol was renewable. For fossil fuels, the students knew that it was from dinosaur remains, non-renewable, polluting and that we get a lot of our fossil fuels from the Middle East. On this last point, they had many opinions that we should not have to get supplies from the Middle East. After the group discussion, packets that included all of the handouts and research guides were handed out. Then we discussed the ultimate goal of the unit by going over the final assessment and rubric. I highlighted the question, "What type of fuel should we be utilizing in mid-Michigan (fossil fuel, conventional ethanol, cellulosic ethanol), or should we be using a mixture of fuels for different purposes?" Finally, at the end of the hour, students wrote down any final opinions or things they learned that day. It seemed like most students thought that we should stick with fossil fuels because it would cost too much to change all of the vehicles to take ethanol. This was completed on the Learning and Opinions handout, and was repeated at the end of each day. The purpose of the Learning and Opinions handout was to organize the students' thoughts after each lesson, and to use as a guide when writing the final assessment. 
On the second day, the students did internet research of fossil fuels, conventional ethanol and cellulosic ethanol. They found the information asked for in the research guide. Students were also instructed to write notes on anything that would help them answer the main question of which fuel we should be using. The majority of students I talked to thought cellulosic ethanol would be best after the internet research because "it's made from left-overs" and "doesn't pollute as much".

Most students needed more time to complete the internet research, so that was completed on the third day. Then in small groups, the students analyzed the GIS maps of the lower peninsula of Michigan. For these maps, the students were to determine what type of supplies we had in mid-Michigan for the three types of fuels. The majority of students I talked to thought that conventional ethanol would be best for mid-Michigan after analyzing the GIS maps because "we have A LOT of farm fields down here". At this point, we had another group discussion to see where the students were in their opinions and so that they could hear each other's opinions. This was also so I could ensure that the students understood the differences between the three types of fuels we were researching.

On the fourth day, small groups completed the Compare Energy Stored in Two Fuels Lab from Lab-Aids. In this lab, the students constructed coffee cup calorimeters to calculate and compare the amount of energy given off from ethanol and kerosene, a fossil fuel. With this lab, the students had conflicting results. According to the answer key from Lab Aids, kerosene should have had the highest energy of combustion. I had some groups getting ethanol and some getting kerosene. These differences created a great opening to discuss lab errors and their effects on the results. During the discussion, I 
made sure that students had the correct answers, so that they could base their opinions on the correct facts. Despite this precaution, there were still a few students who stated incorrect data regarding the energy of combustion of fossil fuels versus ethanol in their final assessments.

On the fifth day, the same groups completed the Compare Combustion ByProducts Lab from Lab-Aids. In this lab, students made observations of the flames of ethanol and kerosene and their by-products. They also calculated which fumes made the water more acidic. This lab was much more dependent on observations than calculations, and therefore easier for the students to understand the results. The differences in the flames of ethanol and kerosene were very apparent and I heard many comments from the students on those differences. Surprisingly, the students also seemed very able to understand that more acidic meant more pollution, especially since they had not learned about acids yet. After both of the labs, many students had different opinions on which fuel was better, depending on if pollution or energy was more important to them. The labs completed all of the data and information the students compiled in order to answer the question of which type of fuel we should be utilizing in mid-Michigan.

The next three days were spent in the computer lab working on the final assessment. The students were encouraged to discuss with other students their opinions and reasons. Students were given the option of writing an essay, making a brochure, or PowerPoint presentation for the final assessment. On the last day, the students took the posttest, which was identical to the pretest. 


\section{Data Collection and Analysis}

The data collected for the research were the pre/post tests, the final assessment, and my daily observations. One of the major things I was looking at for my research was if students learn more effectively and can adequately make and support decisions and opinions, when there is a particular question that has been the focus of the lessons. Because of this, every day of instruction, I made sure to emphasize why we were doing what we were doing. The purpose being to answer the question, "What type of fuel should we be utilizing in mid-Michigan (fossil fuel, conventional ethanol, cellulosic ethanol), or should we be using a mixture of fuels for different purposes?" I would also remind the students that they would be required to state their opinion and support that opinion with explanations from their research or the results from the labs. This pattern was analyzed using the students' final assessments in which they had to state their opinion and support it with data or research. The final assessments were graded using a rubric that focused on whether or not students were able to support their opinions using the information gathered in the different activities from the previous week. Some examples are if the students answered the appropriate questions, discussed limitations of the data, and explained the process they went through to gather all of the information.

Another goal of the research was to develop a bridge between the topic of chemical energy and the real-life topic of sources of fuel. My expectation was that students would learn more effectively. This pattern was analyzed with the pre/post test results administered to the experimental group. The pretest and posttest were identical and were given to the students without warning. This ensured an accurate account of what the students actually knew or learned about the topic of energy, instead of what they 
were able to memorize by studying. The two tests were scored by the same person and scored in the same way. The change in the scores from the pretest to the posttest determined how much the students learned about chemical energy from the lessons. A two sample t-test was used to determine if there was a significant change in the learning of the students. A calculation of normalized gain was also used in order to determine the magnitude of the effect of instruction.

The control group was given the posttest only, which was scored by the same person and in the same way as the experimental group's tests. A two sample t-test was used to determine if there was a significant difference between the posttests of the experimental group and the posttests of the control group. This calculation determined if the teaching unit had added value to the learning outcomes of the regular curriculum.

Finally, the goal of my observations was to look for patterns in what the students were learning from the lessons, and the quality of their discussions throughout the lessons. During the lab experiments, I monitored the development of the students' observation skills, which are an integral part of the practice of science and science literacy. I also made general observations following grading the students' final assessments to determine if students were learning to write in their own voices, or just repeating facts. This last observation was a key component. In my teaching experience, even upper level students would repeat word-for-word what they found on the internet, instead of forming their own opinions. As teachers, we strive to create future citizens who are able to research and have an informed opinion on a topic. I was trying to determine if this teaching unit was able to succeed in that goal. 


\section{Summary}

The study was conducted in November 2010 and March 2011 with the General Chemistry students at Fowlerville High School in Fowlerville, Michigan. The study attempted to determine if there were significant learning gains from the teaching unit and if the students were able to support their opinions with explanations. The experimental group was given a pretest, presented with a teaching unit about fuel sources, then given a posttest and completed a final assessment. The control group was given a posttest only. The following chapter will discuss and analyze the data and results in detail. 


\section{Chapter 4}

Results

\section{Introduction}

Two different assessments were used in the study. A pretest and identical posttest (see Appendix A) were given to the experimental group in Fall 2010. A control group was given a posttest only in Spring 2011. The pre/post test was designed to determine if there were learning gains for the students who were taught the unit. Giving only the posttest to the control group determined if the teaching unit made a difference in student learning about fuel sources for those taking the standard General Chemistry course. A final assessment of the fuel sources investigation was also used to determine if students were able to effectively make informed decisions about fuel sources and support those decisions with complete explanations. Finally, data from teacher observations will also be presented.

\section{Pre/Post Test Results}

The experimental group consisted of 77 students in three different General Chemistry classes all taught by the same teacher. The students took a pretest on the first day of the unit, before anything pertaining to the unit was discussed as a group. This test was an evaluation of the topic of fuel sources, specifically ethanol (cellulosic and conventional) and fossil fuels. The students were not told of the subject of this unit beforehand. The pretest should be an accurate representation of what the students knew about the fuel sources of ethanol and/or fossil fuels before the unit was taught. Then, on 
the last day of the unit, the students were given a posttest that was identical to the pretest. Again, they were not warned of this test, so the test should be an accurate representation of what information the students learned and retained from the unit. The results of the tests for all three classes combined (see Table 2) were as follows: pretest mean $-12.3 \%$ [13.1], posttest mean $-54.2 \%$ [23.2], for an average gain of $41.9 \%$ [22.4].

Table 2: Pre/Post Test Comparison: Experimental Group

\begin{tabular}{cccc}
\hline Class & $\begin{array}{c}\text { Pretest Percent } \\
\text { Mean[SD] }\end{array}$ & $\begin{array}{c}\text { Posttest Percent } \\
\text { Mean[SD] }\end{array}$ & $\begin{array}{c}\text { Gain Percent } \\
\text { Mean[SD] }\end{array}$ \\
\hline & 12.5 & 50.3 & 37.8 \\
First Hour $(\mathrm{N}=24)$ & {$[14.6]$} & {$[21.3]$} & {$[17.1]$} \\
& & & \\
Second Hour $(\mathrm{N}=22)$ & 16.1 & 63.9 & 47.8 \\
& {$[14.2]$} & {$[25.4]$} & {$[26.7]$} \\
Fourth Hour $(\mathrm{N}=31)$ & 9.5 & & \\
& {$[10.6]$} & 50.3 & 40.8 \\
& & {$[21.6]$} & {$[22.4]$} \\
All Classes $(\mathrm{N}=77)$ & 12.3 & 54.2 & 41.9 \\
& {$[13.1]$} & {$[23.2]$} & {$[22.4]$} \\
\hline
\end{tabular}

On average, the students made significant gains in the posttest $(\mathrm{M}=54.2$, $\mathrm{SD}=23.2)$, when compared to the pretest $(\mathrm{M}=12.3, \mathrm{SD}=13.1, \mathrm{t}(76) 13.7, \mathrm{p}<0.001)$.

The results show that the students' knowledge of fuel sources and chemical energy was very low to start with, and that the learning gains of the experimental group were significant. However, a mean score of $54 \%$ on the posttest is not a passing grade. Since the students were given only five days of actual instruction, the scores on the 
posttest could possibly be improved with extended time spent on instruction. The standard deviation of the learning gains was also quite high, indicating a large spread of scores on the posttest. The lowest posttest score was a $0 \%$ by a student who had also scored $0 \%$ on the pretest. The student possibly did not try on either the pretest or the posttest. The highest posttest score was a $100 \%$, by a student who had originally scored a $13.3 \%$ on the pretest. This student also had the largest learning gains of the entire experimental group. Forty-one students scored less than $60 \%$ on the posttest, which is a failing score according to the Fowlerville High School grading scale. The remaining 36 students scored a $60 \%$ or higher, with 11 of those students scoring $80 \%$ or higher. The low mean score on the posttest and the large standard deviation show that there is room for refinement of the teaching unit, however, the large learning gains show that the teaching unit was effective.

These results support my belief that using a teaching approach which involves the unit was effective in increasing the students' knowledge of fuel sources. The results also suggest that using an instructional approach that connected to the students' everyday lives was effective. The results are encouraging, because they indicate that students were able to retain significant knowledge without studying. This suggests that connecting learning to students' backgrounds enhances their memory function.

In Spring 2011, the test was also given to a control group of students at the same school who were completing the course in General Chemistry, but had not been taught the unit on fuel sources. This was to determine if the unit was teaching students concepts that they would not normally be getting with the current curriculum. There were 61 students tested and the average grade on the posttest was a 25.14\% [15.22]. A t-test was 
applied to determine if there was a difference between posttest data for the classes I taught the unit to and the other Chemistry classes. On average, there was a significant difference between the posttest data of the experimental group $(\mathrm{M}=54.2, \mathrm{SD}=23.2)$ and the control group $(\mathrm{M}=25.14, \mathrm{SD}=15.22, \mathrm{t}(137) 8.78, \mathrm{p}<0.001)$. The mean score of the experimental group's pretest $(\mathrm{M}=12.3, \mathrm{SD}=13.1)$ was lower when compared with the mean score of the control group's posttest $(\mathrm{M}=25.14, \mathrm{SD}=15.22)$. This indicates that the control group students were learning some of the concepts covered in the teaching unit through the conventional General Chemistry curriculum, but that the teaching unit and my approach was more effective at increasing student learning than the regular curriculum. In summary, the data showed that instruction was effective in improving learning gains, and that the magnitude of the learning gains would not have occurred through the standard General Chemistry course.

To test the results further an effective size analysis was conducted, using gains analysis. This was intended to determine the order of magnitude of the observed instructional effect. The method proposed by Hake (1998) was applied to the analysis to determine the magnitude of the effect. Hake used the normalized gain $<\mathrm{g}>$ which he defined as the average increase in the students' scores divided by the average increase that would have resulted from all students scoring perfect on the post-test (see equation below).

$$
<g>=\frac{\text { averagegain }(\%)}{\text { maximumpossiblegain }(\%)}=\frac{\text { posttest averagescore }(\%)-\text { pretest averagescore }(\%)}{100-\text { pretest averagescore }(\%)}
$$


According to Hake, a normalized gain greater than 0.7 is considered to have a high effectiveness, less than 0.7 and greater or equal to 0.3 is considered to have a medium effectiveness, and less than 0.3 is considered to have a low effectiveness.

Table 3 indicates the normalized gains of the entire experimental group which includes all three of the classes, and then the experimental group separated by class and by gender. Based on the criteria, the normalized gains for the entire group were medium. When the group was separated by class and by gender, all normalized gains were also found to be medium. This shows that the unit taught had consistent effectiveness throughout the day and to both genders. However, a medium effectiveness shows that there is room for improvement in the unit, in order to have students be able to retain more of the information learned.

Table 3: Normalized Gains

\begin{tabular}{cc}
\hline Group Tested & Normalized Gain $(<\mathrm{g}>)$ \\
\hline All Classes $(\mathrm{N}=77)$ & 0.48 \\
1st Hour $(\mathrm{N}=24)$ & 0.55 \\
2nd Hour (N=22) & 0.44 \\
4th Hour (N=31) & 0.44 \\
Male $(\mathrm{N}=47)$ & 0.55 \\
Female $(\mathrm{N}=30)$ & 0.43 \\
\hline
\end{tabular}




\section{Final Assessment}

The students also had a final assessment for the unit, in which they were asked to form an opinion about fuel sources (see Appendix B). This opinion had to be supported with data obtained from the two labs performed in class, and from their internet and GIS map research. This assessment was to determine what instructional strategies would support the development of the students' abilities to make and adequately support informed decisions about fuel sources. The students were given the option of writing a paper, or designing a brochure or flyer, or PowerPoint presentation for the final assessment. A choice of format was given to students in order to accommodate several learning styles. Students worked on the final assessment for three days in class and all students had access to individual computers with internet access for the entire three days in class. The rubric for the final assessment (see Appendix C) was designed to specifically grade the skills of supporting opinions with facts and making conclusions. All points scored on the rubric related to components of one or both of these skills. The average scores on the final assessment for the three classes are shown below in Table 4.

Table 4: Final Assessment Scores

\begin{tabular}{cc}
\hline Group Tested & Final Assessment Grade (\%) \\
\hline $1^{\text {st }}$ Hour & $62.2[19.4]$ \\
$2^{\text {nd }}$ Hour & $82.9[11.2]$ \\
$4^{\text {th }}$ Hour & $63.6[16.9]$ \\
All Classes Combined & $68.3[18.6]$
\end{tabular}


Since the average grade for the final assessment was a passing grade for all three classes, this shows that the students were able to make and adequately support their informed decisions about fuel sources. That being said, the low passing scores, especially of first hour and fourth hour, show that while the students could perform the skills of supporting opinions with facts, and writing conclusions, these skills were challenging for many students to perform well. These results support my belief that these are skills that many students are not proficient in. Because these skills are both integral parts of the science literacy requirements, teachers should not only be instructing students in how to perform these vital skills, but also giving them adequate practice with the skills throughout the school year.

While grading the final assessments, I noticed a few trends in the results that are discussed below. Even though all students were told that no matter what format they chose, they needed to have all of the components of the rubric included, in general, students who wrote traditional papers seemed to fulfill more of the requirements of the rubric than students who did PowerPoint presentations or brochures/flyers. My prediction was that less academic students were choosing PowerPoint presentations because they thought that it was easier to do than writing a paper. The average grade on the final assessment of all students who wrote traditional papers, and the average grade of all students who did other formats for each of the classes were calculated and compared. While I was correct that the average score of students who wrote papers was higher by $2 \%-13 \%$, in all three of the classes (see Table $5, \mathrm{pg}$. 35), according to a t-test, the difference between the averages was not statistically significant in any of the classes. 
Table 5: Final Assessment Format Comparison

\begin{tabular}{cccc}
\hline Assessment Format & $1^{\text {st }}$ Hour & $2^{\text {nd }}$ Hour & $4^{\text {th }}$ Hour \\
Traditional Paper & $\begin{array}{c}66.8 \% \\
(\mathrm{~N}=17)\end{array}$ & $\begin{array}{c}84.9 \% \\
(\mathrm{~N}=11)\end{array}$ & $\begin{array}{c}64.6 \% \\
(\mathrm{~N}=10)\end{array}$ \\
PowerPoint, Brochure, Flyer & $\begin{array}{c}53.6 \% \\
(\mathrm{~N}=9)\end{array}$ & $\begin{array}{c}80.4 \% \\
(\mathrm{~N}=9)\end{array}$ & $\begin{array}{c}63.1 \% \\
(\mathrm{~N}=19)\end{array}$ \\
\hline
\end{tabular}

After grading all of the final assessments, I started to wonder if there was any correlation in the amount of information the students learned/knew about fuel sources and their ability to support their opinions with facts and make conclusions dealing with fuel sources. To determine if there was a correlation, I compared the students' scores on the posttest, a representation of what they learned/knew, and their score on the final assessment, a representation of their ability to support their opinions (see Table 6). In general, there was a direct correlation between the students' scores on the posttest and their scores on the final assessment. This supports my opinion that the more students know about a subject, the easier it is to support their opinion on that subject.

Table 6: Posttest/Project Comparison (for all classes combined)

\begin{tabular}{ccc}
\hline Number of Students & Posttest Score & Average Project Score \\
\hline 40 & $<60 \%$ & $60.25 \%$ \\
24 & $60 \%-80 \%$ & $74.58 \%$ \\
10 & $>80 \%$ & $87.20 \%$ \\
\hline
\end{tabular}




\section{Observations}

Day 1 of the unit was the introduction to the unit and group brainstorming about ethanol and fossil fuels. Since I was not the regular classroom teacher, I did not know the students, so the brainstorming session was slow to start with. Overall, students did not really know anything about the fuel sources except that ethanol comes from corn and fossil fuels from dinosaur remains. This was supported by the results of the pretests, which had very low scores for all classes.

On Day 2 of the unit, the students were separated into pairs to work on the computer for internet research. The students seemed to have difficulty getting started with the research. If the previous discussion could be held immediately before students start researching, this could be improved. This solution would require a block schedule, or more days for researching. Some of the items on the research guide seemed too complicated for the students to really understand, so a simplification might be required. The students need to understand the comparisons of the fuel sources that they are researching in order to be able to form opinions on which fuel source is better for the area. When small groups of students were interviewed at the end of the unit, all students said that they felt that the internet research was the least useful to them of all of the activities. This could be because the research occurred so early in the unit, or because they did not fully understand what they were researching.

On Day 3 students finished the internet research and then we analyzed the GIS maps for required resources of the different fuel sources. Use of the maps was much more successful than the internet research, because it was very simple for the students to analyze and determine which fuel source had better resources in the area. At the end of 
this lesson, I asked the students if their opinion of which fuel source was better for the area was changing. Some students said yes, others said no, but all students said that their opinions were getting stronger as they found more information.

During Day 4, the students completed the Lab-Aids "Comparing Energy" Lab in small groups. The procedure of this lab was simple enough that most groups did not need much assistance from the instructors, but the calculations of this lab had to be discussed as a large group to ensure that students understood the meaning of the results. On Day 5, the "By-Products" lab was performed in the same small groups. This lab had fewer calculations and was based more on qualitative observations. The students seemed to understand the significance of this lab more in relation to choosing the best fuel source for the area. It was very important to go over the lab results and calculations with the class at the conclusion of each lab to ensure complete understand of the meaning of the results. However, even with this precaution, some students had various misconceptions stated in their final assessments. For instance, there was one student in fourth hour who thought that fossil fuels produced acid rain, but ethanol gave off pollution. In her mind pollution was worse than acid rain, so she concluded that fossil fuels were better for the environment. Also, there were about four students who incorrectly stated that ethanol produced more energy than fossil fuels produce, because that is what their lab group concluded from their calculations. Obviously, there is no way to avoid all of the misconceptions of students, but it is important to be aware of and try to correct the common misconceptions.

The final three days of the unit were spent in the computer lab working on their final assessments. Many students discussed with each other the advantages and 
disadvantages of the different fuel sources. This collaboration was excellent practice for the students, since it would be required in almost any job. I also observed that students seemed to be able to start composing their final assessments without much trouble. This is probably due to the fact that we had been discussing the advantages, disadvantages, and their opinions of the best fuel sources throughout the week before.

While grading the final assessments, I was very impressed with the students' abilities to voice their own opinions. In the past, when I have had students write papers, even my best honors students would basically re-write what they had read from the internet. These students were definitely writing with their own voices, and referring to facts learned from the various activities, in very natural ways that made their arguments that much stronger. I believe that this is due mostly to two factors. One, that I emphasized many times every day that the whole purpose of everything we were doing was to help answer the question of which fuel source would be better in mid-Michigan. This put a purpose to the various activities. Two, because most of the students were of driving age, and many have family members who worked in the auto industry, the topic of fuel sources was something almost every student had an interest in. Therefore, I think that in order to obtain your students' true opinions and scientific conclusions on an issue, all activities must have a purpose in helping them form that opinion, and it must be an issue pertinent to the students.

\section{Summary}

Through this study, I found that the teaching unit enabled students to effectively learn the concepts in General Chemistry that they would not normally have learned 
through the traditional course. Furthermore, these concepts were important and were connected to the Michigan High School Content Expectations. This was observed by the difference in posttest scores between the control group and experimental group. There was also a significant improvement observed between the pretest and posttest scores of the experimental group. The final assessments showed that most students were able to support his/her opinion with explanations and reasoning, but that there is much room for improvement in this area. Overall, I have concluded that the teaching unit had a positive impact on the students and their learning. 


\section{Chapter 5}

Conclusion

\section{Introduction}

The purpose of this study was to determine if using a particular teaching method which made connections between the General Chemistry curriculum and a current reallife topic positively affected student achievement and the students' abilities to make and adequately support informed decisions. Chemistry deals with very small particles, and because it is more difficult to see the processes occurring than with other sciences, students sometimes have difficulty with learning the curriculum. Previous research has shown that students perform better when the science content they are learning is connected to prior knowledge. Student interest also increases when the content is connected to their everyday lives. The goal of the research was to look for connections among content-driven problem-based learning, achievement, and the students' abilities to support decisions with explanations.

\section{Discussion of Results}

The study was designed to use prior knowledge of fuel sources as a foundation to teach concepts in General Chemistry. The results showed that the students experienced significant learning gains and were able to make and adequately support their decisions about fuel sources. The results also showed that the magnitude of the impact on learning gains was medium and that there is some room for improvement in the teaching unit. 
The results of the study support the approach of connecting the curriculum to student experiences. Students learn by connecting new information to what is already known. The unit of instruction was connected to the Content Expectations for Chemistry, demonstrating that significant content knowledge can be learned by using creative methods that are not strictly textbook-based. Although I have not provided data to support this, I felt that the students' opinions and the "voice" in their final assessments were outstanding compared with previous papers that I have assigned students. I believe that this is due to the fact that the students learned the concepts well.

\section{Limitations of the Study}

There were several limitations to the study. First, I was not the regular classroom teacher and I did not have any previous contact with the students, so I lacked the rapport with the students that their regular teacher would have had. This probably caused students to not take the unit as seriously as they would have if it had been presented by their current instructor. However, because I did not know the students, as a researcher I was able to make unbiased observations. Second, the unit was presented over a five day period with an additional three days for in-class work on the final assessment. Ideally, I would have preferred a full two weeks for the unit. The shortened duration was due to Parent-Teacher Conferences making the second week shorter.

\section{Future Extensions}

The teaching approach used with chemical energy and fuel sources could be extended for use in many of the topics in Chemistry and other sciences. For instance, 
when studying acids and bases, the students could research and perform labs that investigate the many uses of acids and bases versus the possible dangers of them. At the completion, students could lobby for the continued use of acids and bases, or for alternatives that would have fewer side effects. In Earth Science, students could investigate wetland areas and the possible development of those lands. The options are endless, and only require a teacher who is willing to devote extra time for research and preparation.

Another possibility would be to add a service learning dimension to the current unit. Students would be encouraged to connect their learning to issues that are of interest to their community, tying the learning to citizenship and social responsibility in the students. Previous research has shown that this component adds purpose to the learning and increases student interest (Keil, Haney, \& Zoffel, 2009). Students could write letters to members of their local legislature informing them of they have discovered about the best fuel sources for the area. The students could also present their brochures or flyers to segments of the local community informing them of what they have learned.

\section{Summary}

The teaching unit had a positive impact on the students' learning of the General Chemistry curriculum. Although the teaching approach used took extra time, effort, and supplies, the research has shown it to be effective. When the ultimate goal is to increase student learning, then science classrooms should be utilizing connections between the curriculum and previous knowledge, student interests, and current issues or problems, in order to obtain the best results. 


\section{References}

Belt, S.T. et al. (2005). Using a Context-Based Approach to Undergraduate Chemistry Teaching - A Case Study for Introductory Physical Chemistry. Chemistry Education Research and Practice, 6(3), 166-179.

Bodzin, A.M., \& Anastasio, D. (2006). Using Web-Based GIS for Earth and Environmental Systems Education. Journal of Geoscience Education, 54(3), 297300.

Hake, R.R. (1998). Interactive-Engagement Versus Traditional Methods: A SixThousand-Student Survey of Mechanics Test Data for Introductory Physics Courses. American Journal of Physics, 66(1), 64-74.

Jaeger, M. (2009, July). GIS Use in the Classroom. Presented at Future Fuels from Forests Teacher Institute, Michigan Technological University, MI.

Kearney, M. (2004). Classroom Use of Multimedia-Supported Predict-Observe-Explain Tasks In a Social Constructivist Learning Environment. Research in Science Education, 34(4), 427-453.

Keil, C., Haney J., \& Zoffel J. (2009). Improvements in Student Achievement and Science Process Skills Using Environmental Health Science Problem-Based Learning Curricula. Electronic Journal of Science Education, 13(1). Retrieved from http://ejse.southwestern.edu.

Lab-Aids, Inc. (2007). Biofuels: Investigating Ethanol Production and Consumption (39S). Copywrite: The Regents of the University of California

Mattheis, F.E. \& Nakayama, G. (1988). Effects of a Laboratory-Centered Inquiry Program on Laboratory Skills, Science Process Skills, and Understanding in Middle Grade Students. (ERIC Document Reproduction Service No. ED307148) Retrieved from ERIC (Educational Resources Information Center) database.

McNeil, K.L. (2009). Teachers' Use of Curriculum to Support Students in Writing Scientific Arguments to Explain Phenomena. Science Education, 93(2), 233-268.

Michigan Department of Education. (2006). High School Science Content Expectations/Chemistry. 
Muller, D.A et al (2008). Saying the Wrong Thing: Improving Learning with Multimedia by Including Misconceptions. Journal of Computer Assisted Learning, 24(2), 144155.

National Research Council. (1996). National Science Education Standards. Washington, DC: National Academy Press.

Pfirman, S. and the AC-ERE. (2003). Complex Environmental Systems. Synthesis for Earth, Life, and Society in the $21^{\text {st }}$ Century. Arlington, VA, National Science Foundation.

Rivet, A.E. \& Krajcik, J.S. (2008). Contextualizing Instruction: Leveraging Students' Prior Knowledge and Experiences to Foster Understanding of Middle School Science. Journal of Research in Science Teaching, 45(1), 79-100.

Ruiz-Primo, M. et al. (2010). Testing One Premise of Scientific Inquiry in Science Classrooms: Examining Students' Scientific Explanations and Student Learning. Journal of Research in Science Teaching, 47(5), 583-608.

Stormer, B. (2010). Agricultural Cover for the Lower Peninsula of Michigan. [GIS Map] Michigan Center for Geographic Information.

Stormer, B. (2010). Aspen Association Cover for the Lower Peninsula of Michigan. [GIS Map] Michigan Center for Geographic Information.

Von Aufschnaiter, C. et al (2008). Arguing to Learn and Learning to Argue: Case Studies of How Students' Argumentation Relates to Their Scienctific Knowledge. Journal of Research in Science Teaching, 45(1), 101-131. 


\section{Appendix A \\ Fuel Investigations \\ Knowledge Pre/Post Test}

1. What is a fossil fuel? Give an example.

2. What is ethanol?

3. How are conventional ethanol and cellulosic ethanol different from each other?

4. What is the world's largest source of energy today?

5. What is Michigan's primary renewable energy generation source?

6. What is produced when ethanol, $\mathrm{C}_{2} \mathrm{H}_{5} \mathrm{OH}$, is burned in oxygen, $\mathrm{O}_{2}$ ?

7. Two equal amounts of kerosene and ethanol are burned and the amount of energy produced is measured. Which fuel, kerosene or ethanol, will release more energy?

8. Why is ethanol considered a "clean burning" fuel?

9. It has been suggested that Michigan should greatly increase its use of ethanol.

(a) What are two possible advantages of increasing Michigan's uses of ethanol?

(b) What are two possible disadvantages of increasing Michigan's uses of ethanol? 


\section{Appendix B \\ Fuel Investigations: Final Assessment}

The purpose of this unit is for you to be able to take the information you obtained from various sources and experiments, and use that information to form an opinion on a particular scientific issue. This opinion must be backed with solid examples and reasons, also based on your observations and sources. As you get older, your opinions will influence how you vote on particular issues, and who you vote for in elections. To make the most informed decisions, you have to be informed on the issues.

There are two options listed below for you to choose from for the final assessment. Both assessments are based on results from fossil fuel, corn ethanol, and cellulosic ethanol investigations.

Option 1: Persuasion Essay

Write a persuasion essay answering the following question:

What type of fuel should we be utilizing in mid-Michigan (fossil fuel, conventional ethanol, cellulosic ethanol), or should we be using a mixture of fuels for different purposes?

Grading Rubric - See next page for specific points.

Planning (Introduction) - 10 points

Performance

Research/GIS - 5 points

$\mathrm{Lab}-5$ points

Analysis of Questions - 20 points

Application (Conclusion) - 10 points

Option 2: Persuasion Brochure/Flyer/Newsletter

Create an opinion brochure, flyer, or newsletter, in which you will be convincing the reader of your opinion of What type of fuel we should be utilizing in mid-Michigan (fossil fuel, conventional ethanol, cellulosic ethanol), or should we be using a mixture of fuels for different purposes.

Grading Rubric - See next page for specific points.

Planning (Introduction) - 10 points

Performance

Research/GIS - 5 points

$\mathrm{Lab}-5$ points

Analysis of Questions - 20 points

Application (Conclusion) - 10 points 


\section{Appendix C \\ Analytical Rubric: Fuel Investigations Final Assessment}

\section{Planning (Introduction) - 10 points total}

1. identifies a problem/question to investigate (1)

2. formulates opinion and states basic reasons why (3)

3. explains experimental design

i. what questions have to be answered (3)

ii. what was the process you went through (3)

\section{Performance $\mathbf{- 1 0}$ points total}

Research/GIS maps

1. uses reliable sources (1)

2. answers appropriate questions (2)

3. describes and observes accurately and completely (2)

$\mathrm{Lab}$

4. demonstrates knowledge of technique (1)

5. describes and observes accurately and completely (2)

6. correct calculations (2)

\section{Analysis of questions - 20 points total}

1. correctly interprets observed/researched data (5)

2. shows qualitative/quantitative relationships (5)

3. suggests limitations/assumptions affecting data (5)

4. draws conclusions and reasons (5)

\section{Application (Conclusion) - 10 points total}

1. states original opinion and reasons before investigation (2)

2. restates final conclusion and reasons (4)

3. states how information can be used - specifics (4) 


\section{Appendix D \\ Fuel Investigations: Using Chemistry to Make Informed Decisions}

Target Grade and Subject: $10^{\text {th }}-12^{\text {th }}$ grade, Chemistry

Unit Overview: The major goal of this unit is for the students to use the results from the various investigations and research to form their own opinions (based on facts and observations) of various types of fuels (specifically fossil fuels, conventional ethanol, and cellulosic ethanol). The students will be learning about chemical reactions and the energy released in combustion throughout the various investigations. The difference from a conventional lesson is that the students will be learning these Chemistry concepts for the purpose of making an informed decision about fuel sources. This unit strives to give purpose to the lessons. Ultimately, the students should be able to answer the following question: In your opinion, what type of fuel should we be utilizing in mid-Michigan (fossil fuel, conventional ethanol, cellulosic ethanol), or should we be using a mixture of fuels for different purposes, and why?

\section{Learning Objectives:}

Lesson 1

TSWBAT participate in a group discussion about energy.

TSWBAT list their previous knowledge of fossil fuels and ethanol.

TSWBAT summarize their current knowledge and opinions of fossil fuels and ethanol.

Lesson 2

TSWBAT use the internet to research conventional ethanol versus cellulosic ethanol, and basic energy information about fossil fuels.

TSWBAT summarize their current knowledge and opinions of fossil fuels and ethanol.

\section{Lesson 3}

TSWBAT use GIS maps to determine if lower/mid Michigan has better resources for conventional or cellulosic ethanol, and compare to the resources for fossil fuels.

TSWBAT summarize their current knowledge and opinions of fossil fuels and ethanol. 


\section{Lesson 4}

TSWBAT make observations of the fermentation of corn and sugar.

TSWBAT perform a distillation of corn and sugar to produce ethanol and record data and observations.

TSWBAT summarize their current knowledge and opinions of fossil fuels and ethanol.

\section{Lesson 5}

TSWBAT compare the energy stored in kerosene and ethanol with calculations and observations.

TSWBAT summarize their current knowledge and opinions of fossil fuels and ethanol.

\section{Lesson 6}

TSWBAT compare the combustions by-products from kerosene and ethanol. TSWBAT summarize their current knowledge and opinions of fossil fuels and ethanol.

\section{Lesson 7}

TSWBAT work with a group to organize their information from all sources in order to develop a personal opinion on energy.

TSWBAT design a persuasion essay, brochure, flyer, or newsletter that will convince the public of their personal opinion on energy based on the information they found.

\section{Lessons}

Pre-Activity for Instructor: Fermentation (2 days before Lesson 1)

Supplies - Lab-Aids Biofuels Kit and student guide sheets

1. Set up the fermentation from the Lab-Aids Biofuels Kit. This will need to be already running the morning before Lesson 1.

2. You will need to spend 5-10 minutes with the students to explain to them what the fermentation set-up is, and have them write their initial observations of the corn syrup and table sugar in the student guide sheet for the lab. Record daily observations.

Lesson 1: Previous Knowledge, Opinions, and Questions (2 class periods)

Supplies - Whiteboard/chalkboard, Learning \& Opinions page

1. Explain to students that we will be starting a unit on fuels and we will be studying this through investigations.

2. Start out with asking the students to state things that they know about ethanol or fossil fuels. This is a time where they can list everything and anything. Record all answers on board for everyone to see. 
3. Next, it is time for the students' opinions. On a different section of the board, list their current opinions about ethanol or fossil fuels. Again, everything and anything is acceptable.

4. Facilitate a short class discussion about the fuel investigation that students seem to have strong opinions about. (Many of my students' family members currently or have previously worked in the auto industry or have farms.)

5. Hand out the Learning \& Opinions page for the unit. Explain to students that this will be where they record anything they learned that day, or how their opinions have changed. The final assessment for this lesson will be an opinion essay, so they will need to have their information organized and readable.

6. Explain fermentation set-up and student observations.

a. Show students Equation 1 and 2 from Lab-Aids and point out the reactants and products of the chemical reaction and have students check that the equations are both balanced correctly. These should be topics that have been previously learned by the students, so it should be a review.

b. Students will need to predict if corn syrup or table sugar will produce the most ethanol in the fermentation process.

c. Students will be recording their observations of the fermentation process for 5 days, and recording their observations in Table 1 of LabAids student guide.

7. Students will need to get in small groups to determine what questions they have that will help them answer the main question of "What type of fuel should we be utilizing in mid-Michigan?". Some questions they might have could be: How much energy do we get from them? What is the producing process like? What do we have more resources for? This will guide their research.

8. Summary - Students will need to write a short summary of what they learned that day and their opinions of ethanol and fossil fuels. This will be used as a study guide for the final assessment. 


\section{Fuel Investigations: Learning \& Opinions}

QUESTION: What type of fuel should we be utilizing in mid-Michigan (fossil fuel, conventional ethanol, cellulosic ethanol), or should we be using a mixture of fuels for different purposes?

Pre-Opinion: What are your current opinions and knowledge of fossil fuels and ethanol?
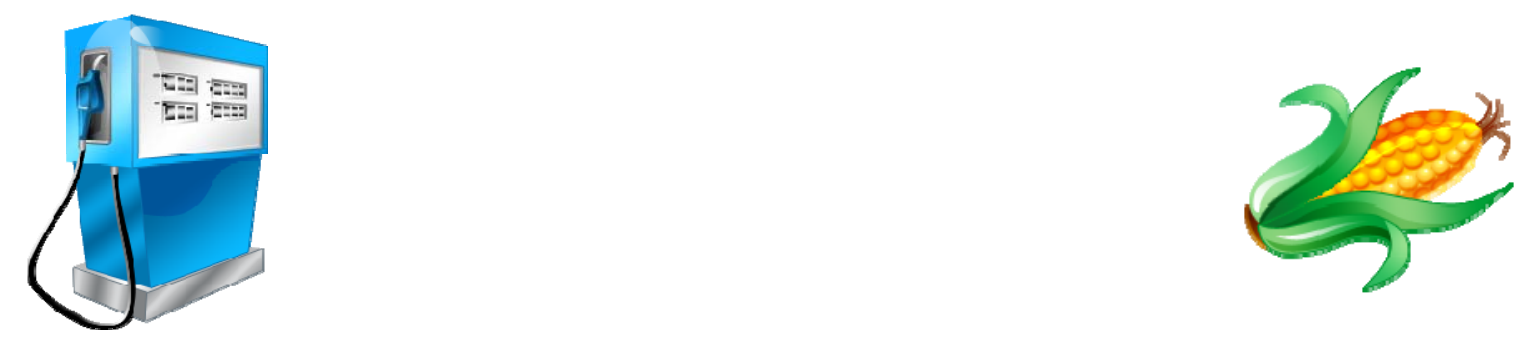

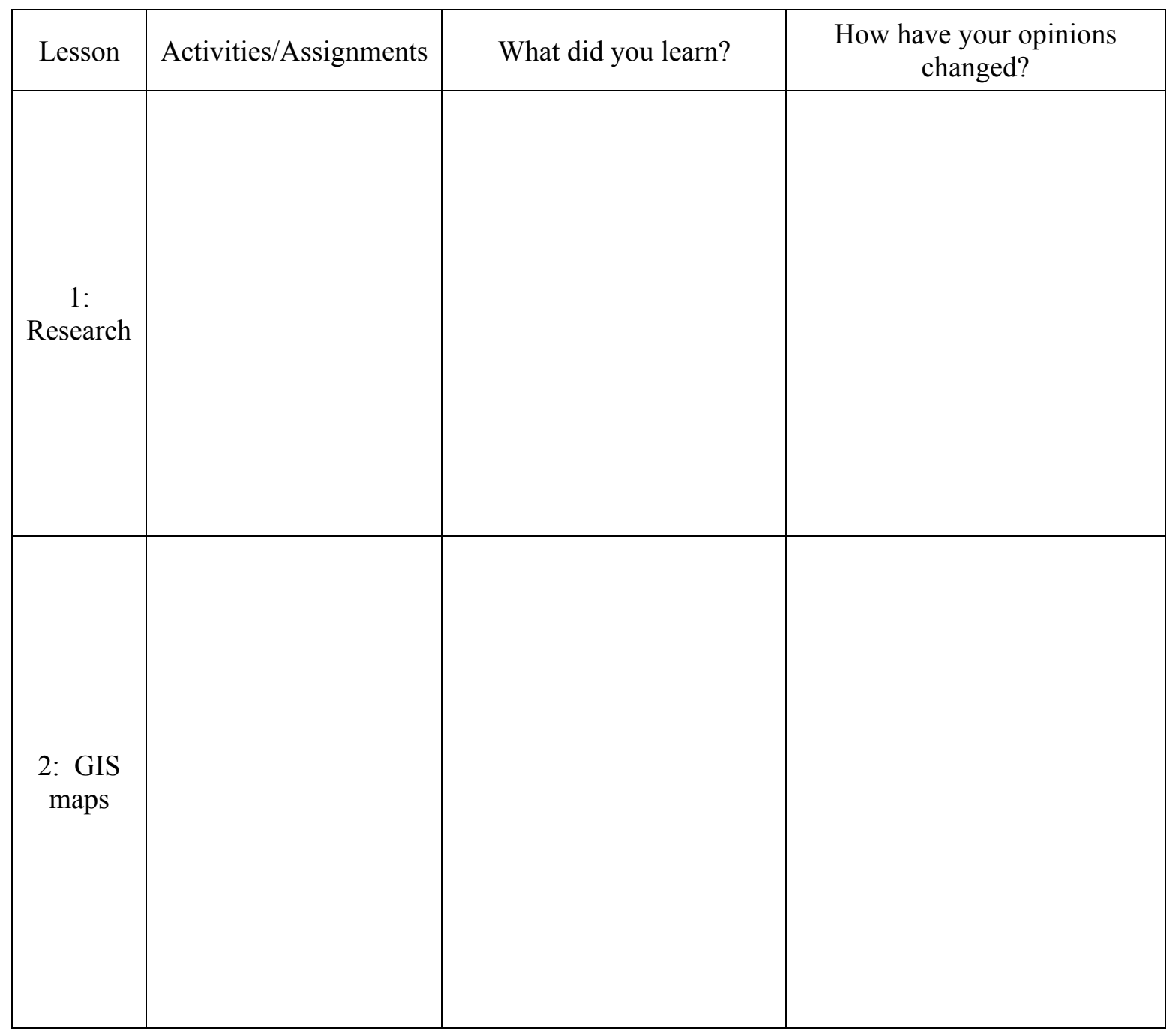




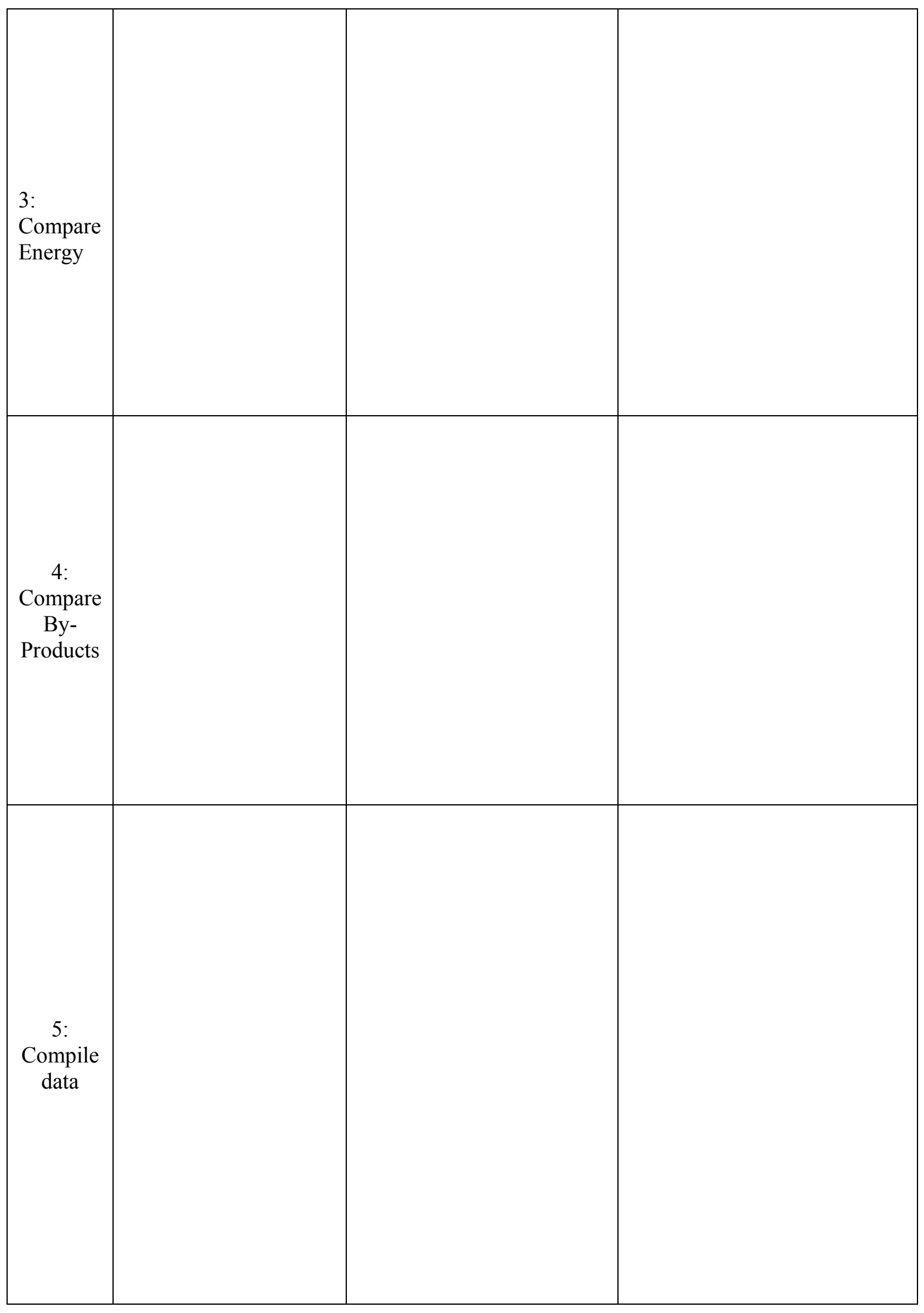


Lesson 2: Research (1 class period)

Supplies: Lab-Aids student guide, Computers (at least 1 for every group), Research Guide page

1. Split students into groups of 3-4 for the rest of the investigations.

2. Have students write their daily observations of the fermentation process in the Lab-Aids student guide sheet.

3. Hand out Energy research guide. Students will be instructed to research ethanol, specifically conventional (corn/soy) ethanol versus cellulosic ethanol, and fossil fuels using the internet.

4. At the end of the hour, all students should fill-in the Learning \& Opinions page for the day. 


\section{Fuel Investigations: Research Guide}

Introduction: At the conclusion of this unit, you will be expected to write an opinion essay answering the question, "In your opinion, what type of fuel should we be utilizing in mid-Michigan (fossil fuel, conventional ethanol, cellulosic ethanol), or should we be using a mixture of fuels for different purposes and why? Explain your answers using solid reasons and backed with many examples from the various investigations." Today is devoted to use of the internet to help you answer this question. I have included some broad information that might be helpful for you to obtain, however, you are going to determine where your specific research leads you.

The Energy Information Administration (EIA), www.eia.doe.gov, is a great place to start your research.

What is a fossil fuel? Where does it come from? How is it refined (processed)?

What is ethanol? Where does it come from? How is it refined (processed)?

How are conventional ethanol and cellulosic ethanol different from each other?

What are the general sources for energy and fuel currently used in Michigan?

How much energy do we currently obtain from fossil fuels?

How much energy do we currently obtain from ethanol?

How much energy do we currently obtain from other renewable sources?

What is Michigan's primary renewable energy generation source? 
What are the resources used/needed for fossil fuels? Do we have those resources readily available in mid-Michigan?

What are the resources used/needed for conventional ethanol? Do we have those resources readily available in mid-Michigan?

What are the resources used/needed for cellulosic ethanol? Do we have those resources readily available in mid-Michigan?

Other things to consider and research - cost of each fuel, what processing of the fuel costs/requires, environmental concerns, etc.

Basic Info

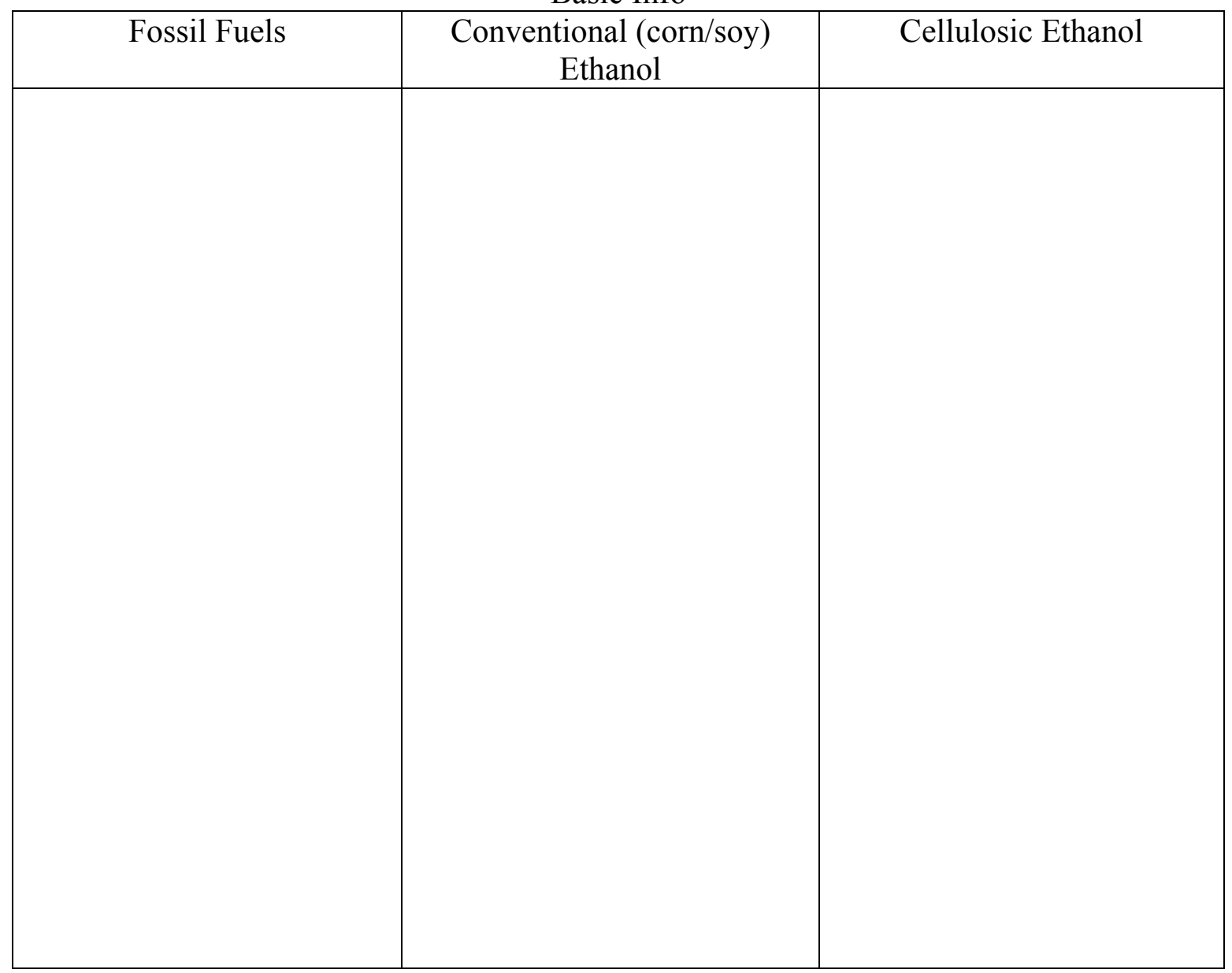


Lesson 3: GIS Maps (10-15 minutes)

Supplies: GIS Maps (1 for tree coverage in your area, 1 for farm fields in your area) on overhead sheet. Search Michigan Geographic Data Library for access to GIS maps, or contact a local forestry department. Oil Production Map for Michigan (from DNRE)

1. Hand out GIS maps of the local area on overhead sheets, and blank map of same area to each group.

2. The students will need to use the GIS maps to determine how much land is available for conventional ethanol (corn/farm fields) and how much land is available for cellulosic ethanol (trees).

3. Students need to compare land available for ethanol, to the number of oil producing wells in the area (see DNRE map)

4. Students should discuss in their groups, what type of ethanol is most convenient for their area, in terms of land use.

QUESTION: What type of fuel should we be utilizing in mid-Michigan (fossil fuel, conventional ethanol, cellulosic ethanol), or should we be using a mixture of fuels for different purposes?

\section{Map of Oil Producing Wells in Michigan (2006, DNRE)}

http://www.michigan.gov/deq/0,1607,7-135-3311 4111 4231-14421--,00.html

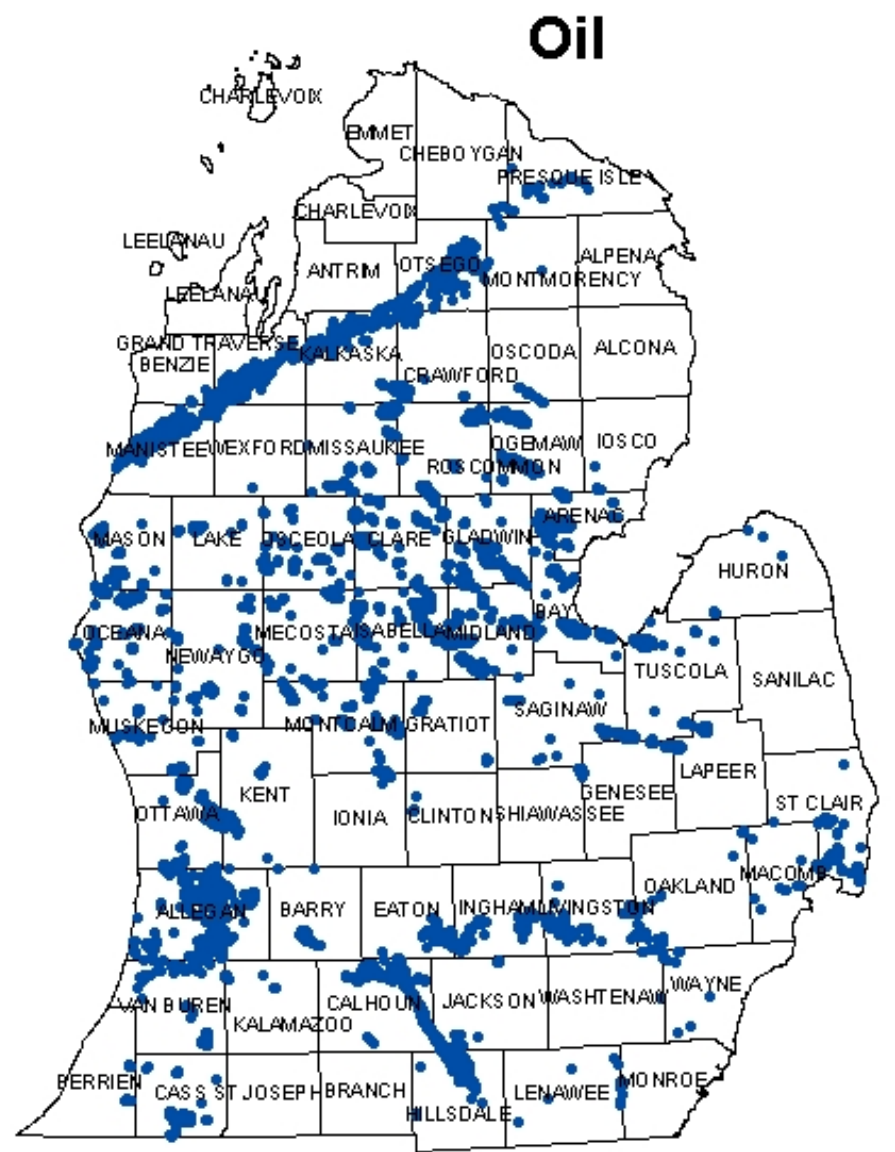




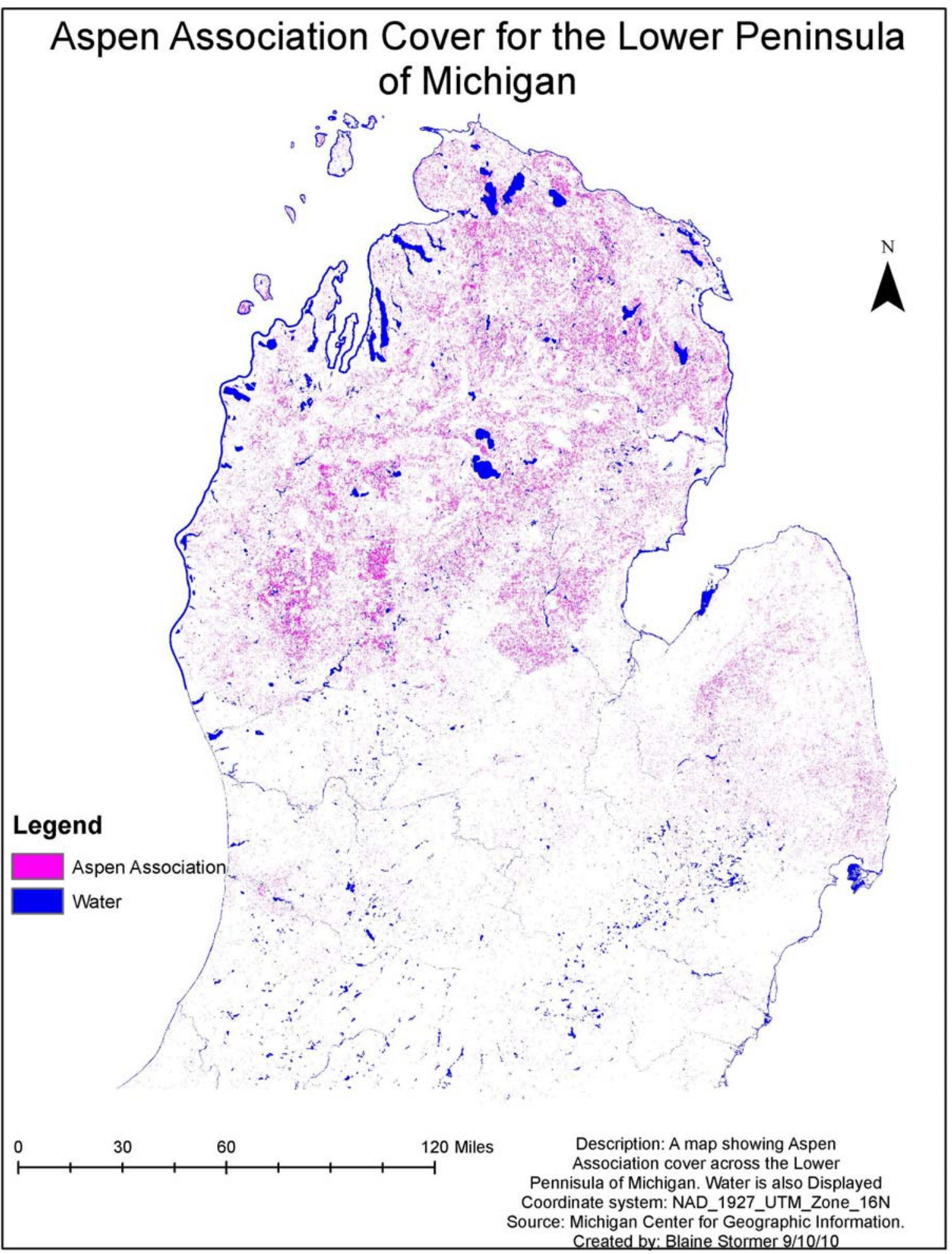




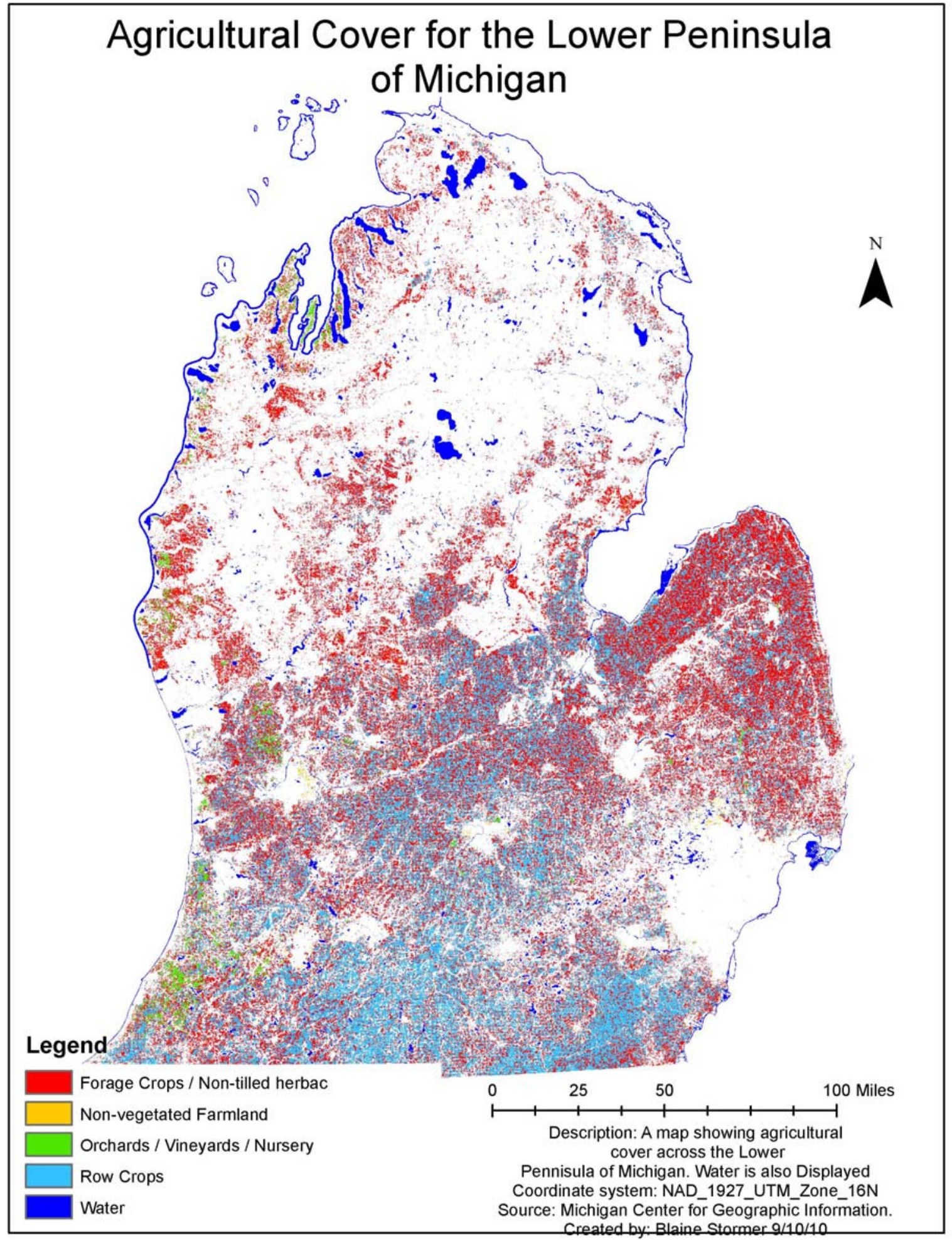


Lesson 4: Distillation of Corn and Sugar (40-45 minutes)

Supplies: Lab-Aids Biofuels Kit, balances, beakers, graduated cylinders, safety goggles

1. Set up distillation at the beginning of class as a demonstration.

2. Perform the two distillation apparatuses according to the Lab-Aids directions.

3. As distillation is occurring, students will need to record observations in Table 2: Results of Distillation.

4. After distillation, students will need to answer the analysis questions for Procedure: Part B.

5. Have students discuss in their groups what conclusions they can make from their observations of the investigations.

6. Go over the students' answers to the analysis questions as a class, to ensure that every student is obtaining the same information.

7. Students should fill in their Learning \& Opinions for the day, including information from the GIS maps and distillation.

Lesson 5: Compare Energy Stored in Two Fuels (1 class period)

Supplies: Lab-Aids Biofuels Kit, matches, graduated cylinder, rulers, pop can, ring stand, clamp, paper clips, thermometers, balance, safety goggles

1. Set up lab stations for 3-4 students for Lab-Aids Biofuels Investigation 2: Comparing Energy Stored in Two Fuels.

2. Students will perform the investigation (pop-can calorimetry) according to the Lab-Aids directions.

3. Students will need to record all of their data in the tables provided and perform all calculations.

4. At the Conclusion of the lab, students will need to answer the analysis questions.

5. Have students discuss in their groups what conclusions they can make from their observations of the investigation.

6. Go over the students' answers to the analysis questions as a class, to ensure that every student is obtaining the same information.

7. Students should fill in their Learning \& Opinions for the day, including information from the GIS maps and distillation.

Lesson 6: Compare Combustion By-Products from Two Fuels (1 class period)

Supplies: Lab-Aids Biofuels Kit, tongs, aluminum foil, plastic bottle with cap, graduated cylinders, safety goggles

1. Set up lab stations for 3-4 students for Lab-Aids Biofuels Investigation 3: Comparing Combustion By-Products from Two Fuels.

2. Students will perform the investigation according to the Lab-Aids directions.

3. Students will need to record all of their data in the tables provided and perform all calculations.

4. At the Conclusion of the lab, students will need to answer the analysis questions. 
5. Have students discuss in their groups what conclusions they can make from their observations of the investigation.

6. Go over the students' answers to the analysis questions as a class, to ensure that every student is obtaining the same information.

7. Students should fill in their Learning \& Opinions for the day, including information from the GIS maps and distillation.

Lesson 7: Summaries (1 class period)

Supplies: Students' completed Learning \& Opinions, all completed activities

1. In their groups, students will need to compile all of their information to discuss their final opinions on the type of fuel that should be used in midMichigan. They should also be discussing what the major supports for their opinions are.

2. All students will need to decide if they would like to write the persuasions essay, or if they would like to make an persuasion brochure, both with the purpose of convincing the reader of the their opinions based on facts and observations.

\section{Assessment Plan}

Formative Assessments:

All of the activities listed above are part of the formative assessments for this lesson, and therefore the students will get feedback on them, but will not be graded on them. This allows the students to learn without being punished with grades. The instructor is responsible for providing immediate, descriptive feedback to students, to ensure they know where they are at with their learning.

Summative Assessment:

The purpose of the lesson is to teach the students about making informed decisions based on scientific facts and observations. Students will only be graded on their understanding of this concept.

Students will be required to write a persuasive essay or brochure/flyer/newsletter answering the following question:

"In your opinion, what type of fuel should we be utilizing in mid-Michigan and why?" 


\section{Appendix E}

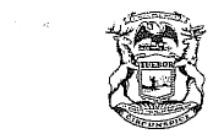

JENNIFER M. GRANHOLM

GOVERNOR
StATE OF Michigan

\section{DEPARTMENT OF ENVIRONMENTAL QUALITY}

LANSING

August 20, 2008

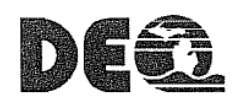

STEVEN E. CHESTER DIRECTOR

Kedmon N. Hungwe

Associate Professor, Science Education

206 Academic Office Building

Michigan Tech University

1400 Townsend Dr.

Houghton, MI 49931

Dear Professor Hungwe:

As the Michigan Department of Environmental Quality's Intern Program Coordinator, I work closely with more than 40 interns each year. Nicole Olszowy ranks among the best.

I have enclosed a project log to provide some detail on Nicole's internship. Nicole served as DEQ Editor, worked with a committee of Authors and experts, and published the Michigan Content Expectations Alignments for our Michigan Environmental Education Curriculum Support. This project called for Nicole's competence with education standards, careful analyses and writing, and clear communication with a group of professionals from a myriad of universities and agencies. Her work was outstanding.

Nicole performed at similar high quality for each and every project. She worked five days per week, full time, and completed 260 hours, always punctual and prepared.

We were able to send Nicole into the field numerous times with various engineers and specialists. She observed environmental work first hand, and I expect her insights will be unique as she returns to the classroom setting. Nicole quickly earned the respect of professionals from DEQ as well as professional educators statewide. I could not have been more pleased with her internship, and I believe she came away with similar respect for the learning experience.

If you have any questions, please contact me at (517) 373-2379.

$$
\text { Sincerely, }
$$

Thomas M. Occhipinti Environmental Education Coordinator

Cc: Brad Baltensperger, Department of Cognitive and Learning Sciences Chair, MTU

CONSTITUTION HALL • 525 WEST ALLEGAN STREET • P.O. BOX 30473 • LANSING, MICHIGAN 48909-7973 www.michigan.gov $\cdot(800) 662-9278$ 


\section{Accomplishment Log Nicole N. Olszowy}

June 30 - August 15, 2008

\begin{tabular}{|c|c|c|c|}
\hline Assignment & Description & $\begin{array}{l}\text { Start } \\
\text { Date }\end{array}$ & $\begin{array}{l}\text { Completion } \\
\text { Date }\end{array}$ \\
\hline $\begin{array}{c}\text { GLCEs/HSCEs } \\
\text { Alignments for MEECS }\end{array}$ & $\begin{array}{l}\text { Proof-reading draft alignments from } \\
\text { unit authors and reformatting all } \\
\text { alignments. } \\
\text { Contacts with authors about changes. } \\
\text { Communication with EMC about } \\
\text { cover page for all units. }\end{array}$ & $6-30-08$ & $8-7-08$ \\
\hline $\begin{array}{l}\text { MEECS Website } \\
\text { Revision (assisted) }\end{array}$ & $\begin{array}{l}\text { Brainstormed revisions for entire } \\
\text { webpage, reformatted "Workshops } \\
\text { and Materials" page, "How to Host a } \\
\text { Workshop", and the "How to } \\
\text { Become a MEECS Facilitator" page. }\end{array}$ & $7-10-08$ & $7-31-08$ \\
\hline $\begin{array}{l}\text { HSCEs Alignment for } \\
\text { Michigan Envirothon }\end{array}$ & $\begin{array}{l}\text { Aligned Envirothon learning } \\
\text { objectives, including the community } \\
\text { service project to Michigan HSCEs }\end{array}$ & $7-15-08$ & $7-24-08$ \\
\hline MEECS Marketing & $\begin{array}{l}\text { Listed possible groups to send } \\
\text { MEECS alignment to. Produced a } \\
\text { list of curriculum coordinators for } \\
\text { MEECS outreach. } \\
\text { Sent email letters to groups we } \\
\text { determined about the new } \\
\text { expectation alignments for MEECS }\end{array}$ & $7-22-08$ & $8-11-08$ \\
\hline $\begin{array}{l}\text { Brochure for DEQ } \\
\text { Environmental } \\
\text { Education Website }\end{array}$ & $\begin{array}{l}\text { Took information from website and } \\
\text { previous drafts to compile a new } \\
\text { draft brochure for use at workshops. }\end{array}$ & $8-1-08$ & $8-6-08$ \\
\hline $\begin{array}{l}\text { Possibility of MEECS } \\
\text { Survey }\end{array}$ & $\begin{array}{l}\text { Compiled information from previous } \\
\text { MEECS surveys to determine if a } \\
\text { new survey is needed. } \\
\text { Reported back that a new survey } \\
\text { would be useful in Spring } 2009 \text { or } \\
\text { Fall } 2009 \text { after we have had more } \\
\text { MEECS workshops. }\end{array}$ & $8-4-08$ & $8-7-08$ \\
\hline
\end{tabular}

